Research Article

\title{
Numerical Investigation into Flutter and Flutter-Buffet Phenomena for a Swept Wing and a Curved Planform Wing
}

\author{
Mario Rosario Chiarelli (iD) and Salvatore Bonomo \\ University of Pisa, DICI, Largo Lucio Lazzarino 1, Pisa 56122, Italy \\ Correspondence should be addressed to Mario Rosario Chiarelli; chiarelli@ing.unipi.it
}

Received 28 June 2018; Accepted 19 December 2018; Published 27 February 2019

Academic Editor: Santiago Hernández

Copyright (C) 2019 Mario Rosario Chiarelli and Salvatore Bonomo. This is an open access article distributed under the Creative Commons Attribution License, which permits unrestricted use, distribution, and reproduction in any medium, provided the original work is properly cited.

\begin{abstract}
The results of numerical studies carried out on high-aspect-ratio wings with different planforms are discussed: the transonic regime is analysed for a swept wing and a curved planform wing. The wings have similar aspect ratios and similar aerodynamic profiles. The analyses were carried out by CFD and FE techniques, and the reliability of the numerical aerodynamic results was proven by a sensitivity study. Analysing the performances of the two wings demonstrated that in transonic flight conditions, a noticeable drag reduction can be obtained by adopting a curved planform wing. In addition, for such a wing, the aeroelastic instability condition, consisting in a classical flutter, is postponed compared to a conventional swept wing, for which a flutter-buffet instability occurs. In a preliminary manner, the study shows that, for a curved planform wing, the high speed buffet is not an issue and at the same time notable fuel saving can be achieved.
\end{abstract}

\section{Introduction}

Improving transport aircraft performance is still an important challenge, particularly given the strong increase in the commercial flight market. Modern technologies and new design configurations are aimed at increasing efficiency, in order to reduce operative costs and pollution. New propulsion systems have been introduced [1], together with lighter, more efficient and/or hybrid materials which can also be used for the manufacturing and monitoring of the safety of aircraft structures [2-9]. There are also new technologies for aircraft control and guidance [10-12] and new aircraft configurations and/or new technical solutions ([2], [13-16]).

In [2], the adoption of folding wing tips enables the wing span to be increased during the flight operations thus reducing the aerodynamic induced drag. Improving both aerodynamic and structural efficiency also represents the main goal for biplane configurations $[15,16]$ or when the use of clean morphing wings is proposed $[13,14]$. In our previous works, a preliminary layout of a wing configuration with a curved planform which considerably increases the aerodynamic efficiency, especially in the transonic regime, was proposed [17-19].

However, recent developments in our research on this wing configuration [20] have led to new areas of study that need further investigation. We have thus conducted further analyses aimed at a more accurate computation of the aerodynamic efficiency of the studied wings and at a more detailed definition and understanding of the aeroelastic instability phenomena which occur for swept and curved wings in the transonic regime.

The first part of the present paper describes the results of a numerical sensitivity analysis. The aerodynamic meshes, developed using commercial software, are based on a structured procedure. Thus, although the planforms of wings are different, the errors due to the numerical approach are of the same order of magnitude. The geometry of the examined wings is described in [20]. For both wings, highly refined meshes were constructed and analysed in the transonic regime by assuming the models as rigid: that is, the 
geometry of the wings is not modified by the aerodynamic loads. The most accurate structured meshes contain about $6,500,000$ cells.

All the simulations were performed using the commercial code ANSYS-Fluent Rel. 15. To test the numerical results, both density-based and pressure-based solvers were used during the analyses [21]. The results obtained enable us to better understand the effect of mesh refinement on the computed values for lift and drag coefficients.

This study confirms results obtained in our previous research [17]: the curved-wing configuration provides a notable reduction in the wave drag due to the transonic regime. This leads to a significant fuel saving, as will be shown in a preliminary case study. In addition, looking at the axial component of the curl of the velocity vector in the wake, for the curved wing, the tip wake vortex has a reduced dimension and the induced drag effects are also reduced.

The results of the sensitivity analysis demonstrate that for the aerodynamic meshes (mid-level meshes) used in the transonic Fluid Structure Interaction (FSI) studies, the lift coefficient is affected by a maximum error of about $10 \%$, while a higher error affects the drag coefficient. In the coupled dynamic analyses, the lift coefficient plays a key role. For this practical reason and in view of the available computational resources, all the coupled dynamics results discussed in this work relate to mid-level aerodynamic structured meshes (made from 400,000 cells).

As is well known, from an aircraft engineering point of view, the aeroelastic instability conditions lead to the definition of a buffet and/or flutter boundary, which represents a technical constraint for the safety of aircraft. In the technical literature, it is assumed that a high speed buffet is related to flow separation occurring on the wing surfaces behind an oscillating shockwave that develops at high altitudes and high Mach numbers. An early example of an airfoil buffet boundary is in [22], examples of buffet onset boundaries for transport aircraft are in [23], and finally an example of wing flutter boundary is provided in [24].

Aeroelastic instabilities can be studied using mathematics and methodologies related to the dynamic equilibrium of nonlinear systems: see, for instance, the works [25-28]. As discussed in $[26,27]$, the physical sources of nonlinearity are in the structure or in the aerodynamic flow field.

At high Mach numbers, the most important aerodynamic nonlinearities relate to shock motions and subsequent flow separation. At low airspeeds, i.e., low Mach numbers, vortex shedding may characterize the unsteady aerodynamics and, in this case, the flutter can be driven by the dynamic-stall-related nonlinearities [28].

The behaviour of a nonlinear system can be represented by a bifurcation diagram, which can be used both for nonlinear static problems, e.g., a postbuckling problem [3], and nonlinear dynamic problems, e.g., the identification of limit cycle oscillations (LCOs) for aeroelastic problems ([25-28]). The flutter speed is reached when self-sustained oscillations occur. As the dynamic problem is nonlinear, these oscillations have a finite amplitude (LCOs of a constant amplitude are established). In general, with benign nonlinearity, the amplitude of LCO increases if the Mach number increases.
In this case, supercritical or postcritical stable paths can be drawn in the bifurcation diagrams (see Figure 16 of [25]), and the stronger the nonlinearities are, the smaller the LCO amplitudes will be (see Figure 1.a of [27]).

According to the definitions given in [27], a stability boundary can be found for which the oscillations are slowly diverging or constant in amplitude (LCO), and sometimes safe conditions can be recovered by a further small increase in the Mach number. This behaviour is one of the three types of flutter found for the BACT Model at high subsonic Mach number. In this case, the type of instability is termed "single-degree-of-freedom flutter" and the stability boundary is referred to as "a chimney" [27].

For the fully transonic regime, in our coupled numerical analyses, a single-degree-of-freedom flutter, characterized by a slowly diverging LCO, was observed for the swept-wing model. On the other hand, for the curved-wing model, in the supercritical regime the increase in amplitude for the estimated LCO (not stable) due to an increase in the Mach number was more rapid: in this case a classical flutter condition occurs [27]. Just above the flutter speed, the LCO amplitudes of the swept wing are smaller compared with the curved-wing amplitudes. In other words, according to the physical definition given in [27], a stronger nonlinearity affects the swept-wing behaviour close to the instability condition. The source of this strong nonlinearity is related to the transonic flow which becomes unstable: that is, buffeting takes place.

There are many works in the literature on transonic buffet. They provide definitions, methodologies, and numerical and experimental results aimed at understanding the very complex phenomena related to the behaviour of aircraft wings, which undergo nonlinear dynamic loads produced by the aerodynamic pressure field which develops in the transonic regime.

The transonic buffet mechanism is typically studied for two-dimensional aerodynamic profiles (see for example the works [29-36]). There are several studies related to the interaction of the buffet with flutter. An elastic motion of the airfoil is often simulated, and consequently, the system stability characteristics and the effects of pitching and/or bending motion on the aerodynamic coefficients are investigated ([37-46]). Forward and backward shock wave oscillations can be coupled with the pitching or plunging of an airfoil, thus leading to unstable aeroelastic conditions. Such instability generally depends on both the Mach number and the airfoil's angle of attack.

Recently, there has been more focus on understanding the characteristics of three-dimensional unsteady phenomena associated with the transonic aerodynamics that evolve on swept wings ([47-50]). In [51], there is a review of several scientific studies on transonic buffet.

In the case of three-dimensional wings, the pressure distribution and the boundary of the sonic zone are strongly affected by the geometry of the aerodynamic surfaces (profiles, tapering ratio, aspect ratio, angle of sweep, twist distribution, and so on) and the effects of elasticity of the structures plays an even more important role ([52-55]). In [56], there is a review focussing on the nonlinear phenomena 
related to transonic aerodynamics and/or nonlinear structural behaviour of high-aspect-ratio wings.

From a more general point of view, both for twodimensional and three-dimensional systems, the supersonic zone tends to approach an unstable configuration, which occurs both for rigid and elastic models. In the transonic regime, in the fluid domain around a profile or around a wing, two distinct regions coexist: a subsonic and a supersonic region. The stability of this coexistence depends on the status characteristics of the fluid, which can be thought of as an elastic medium. All elastic media have their own frequencies and modes of vibration. In the case of a fluid, frequencies and modes associated with the pressure field must be taken into account and accurately computed.

A contribution to interpreting transonic aeroelastic instabilities is thus proposed here aimed at understanding, in a preliminary manner, the physical mechanisms on which these phenomena are based.

Our results show that, as expected, when the operating conditions approach the stability boundaries, the flutter mechanisms involve a very large amount of energy. In addition, when a classical flutter occurs, this type of instability does not depend on trim conditions. This has an important consequence: it is not necessary to simulate, for example, the effects of the inertia loads (gravity effects), because the change in the wing shape induced by these loads does not affect the mechanisms of the instability. In this case, the Mach number is the main physical field parameter. If a direct transient coupled analysis is carried out, as in the present work, close to the flutter conditions, there is a strong variation in both shape and dimension of the supersonic zone. However, in this case the oscillations of the shock wave are only a consequence of the wing mechanical oscillations.

On the other hand, if the dynamic instability involves both the supersonic zone and the shock waves at its boundary as key players, the dynamics response of the wing depends on both Mach number and the angle of attack: i.e., a flutter-buffet interaction occurs. In this latter case, the very strong aerodynamic nonlinearities lead to a form of instability that is weaker but more insidious compared to a classical flutter. In this case, by running different analyses corresponding to a fixed value of Mach number but with different angles of attack, different values of the overall damping parameter were estimated.

It can also be shown that the pressure field around the deformed wing vibrates according to a specific and instantaneous frequency spectrum, whose fundamental frequency falls close to the critical natural frequencies of the wing structure. To clearly identify the frequency spectrum of the pressure field, a specific rigid CFD analysis needs to be carried out, in terms of a deformed wing configuration produced by the aerodynamic loads. This demonstrates the nonnegligible role of the trim conditions correctly defining the nonlinear dynamic behaviour of a wing.

In the present study, when the flutter-buffet instability occurs (two elastic media interact: the wing structure and the fluid), the fundamental frequency of the pressure field corresponds to the frequency of the buffet which develops on the rigid-wing model. This model has a deformed shape, which corresponds to the mean value of the nonlinear dynamic displacement history.

By adopting a numerical technique based on the analysis of the dynamic response of a structure which undergoes unsteady aerodynamic loads (that is, a series of fluid structure interaction analyses performed using commercial software), a classical flutter condition can be clearly recognized due to the rapid increase in the curved-wing oscillation amplitude. In this case, the interaction between bending and torsion is clearly evident. Conversely, in the cases examined, when the flutter-buffet occurs a slight increase of the swept-wing oscillation amplitude can be observed. The reduced amplitude of the oscillations is related to the smaller amount of energy involved in this instability. With regard to flutter, the work done by the aerodynamic field on the wing structure depends on the effects of direct and indirect aerodynamic derivatives (lift and moment coefficients) which are a function of both the Mach number and reduced frequency. A classical flutter mechanism takes place if at least two elastic degrees of freedom interact. In the early phase of the flutter-buffet, the work done by the aerodynamic field on the wing structure depends on forces produced by the periodic and self-sustained vibrations of the pressure field (buffet) excited by the inevitable perturbations that arise near the wing surface. In this case, as discussed in [20], the aeroelastic instability of the swept wing occurs with a predominant contribution of just one elastic degree of freedom (i.e., a single-degree-offreedom flutter is now activated) and, in the present study, the role of bending alone is evident. Finally, for the same values of altitude and lift coefficient, the transonic buffeting of the swept wing occurs for a lower Mach number compared with the curved-wing flutter instability: i.e., the curved planform wing is characterized by higher stability margins. A detailed graphical representation of these results is outlined in this paper.

\section{CFD Results for Rigid-Wing Models}

Drag reduction is one of the advantages of the curved planform wing. To confirm this advantage, previously obtained [17] refined meshes were set up for the swept-wing and for the curved-wing models. Figures 1 and 2 show the models of the two half wings, with $\mathrm{AR}=9.5$ (details on the wing geometries can be found in [20]).

A blocking technique [20] was adopted to build structured meshes with the same topology for swept and curved models. The entire meshes are made up of $6,490,550$ HEXA-8 elements and 6,570,662 nodes (Figure 3 ).

The surface meshes of the wing models are composed of 44,574 QUAD-4 elements and 44,699 nodes. Figure 4 shows the surface mesh of the curved wing, while Figures 5 and 6 show, as an example, the mesh layout at the tip of the curved-wing model and at the lateral side of the curved-wing mesh volume, respectively.

The polar curves, computed for rigid-wing models, were estimated and compared for an altitude of $10,000 \mathrm{~m}$, a Mach number of 0.85 , and an estimated Reynolds number of 5.67 $\times 10^{7}$. Steady state density-based analyses were executed; 


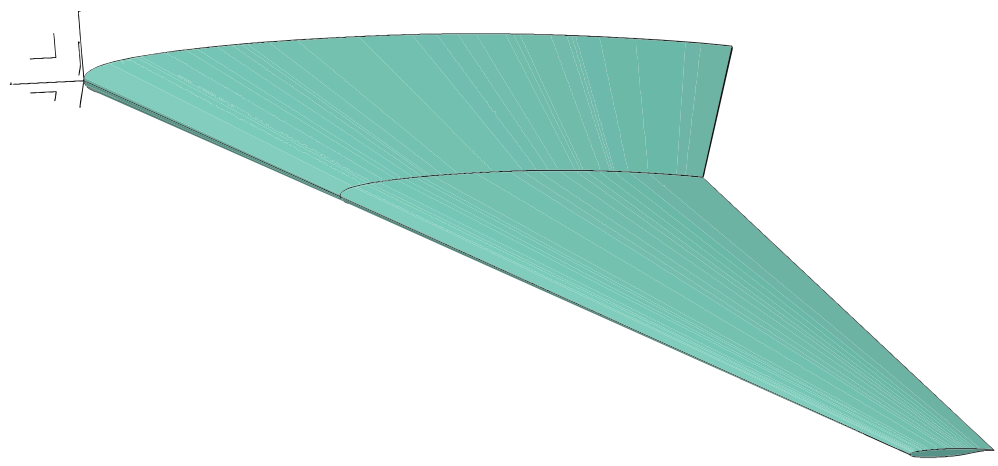

FIGURE 1: Swept-wing model.

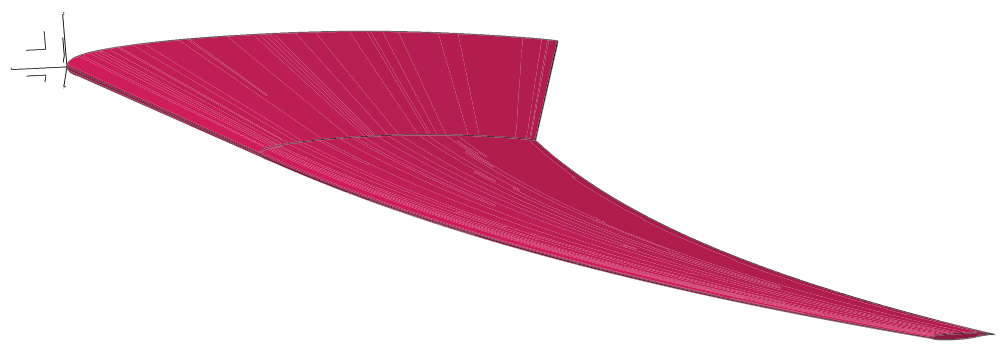

FIgURE 2: Curved-wing model.
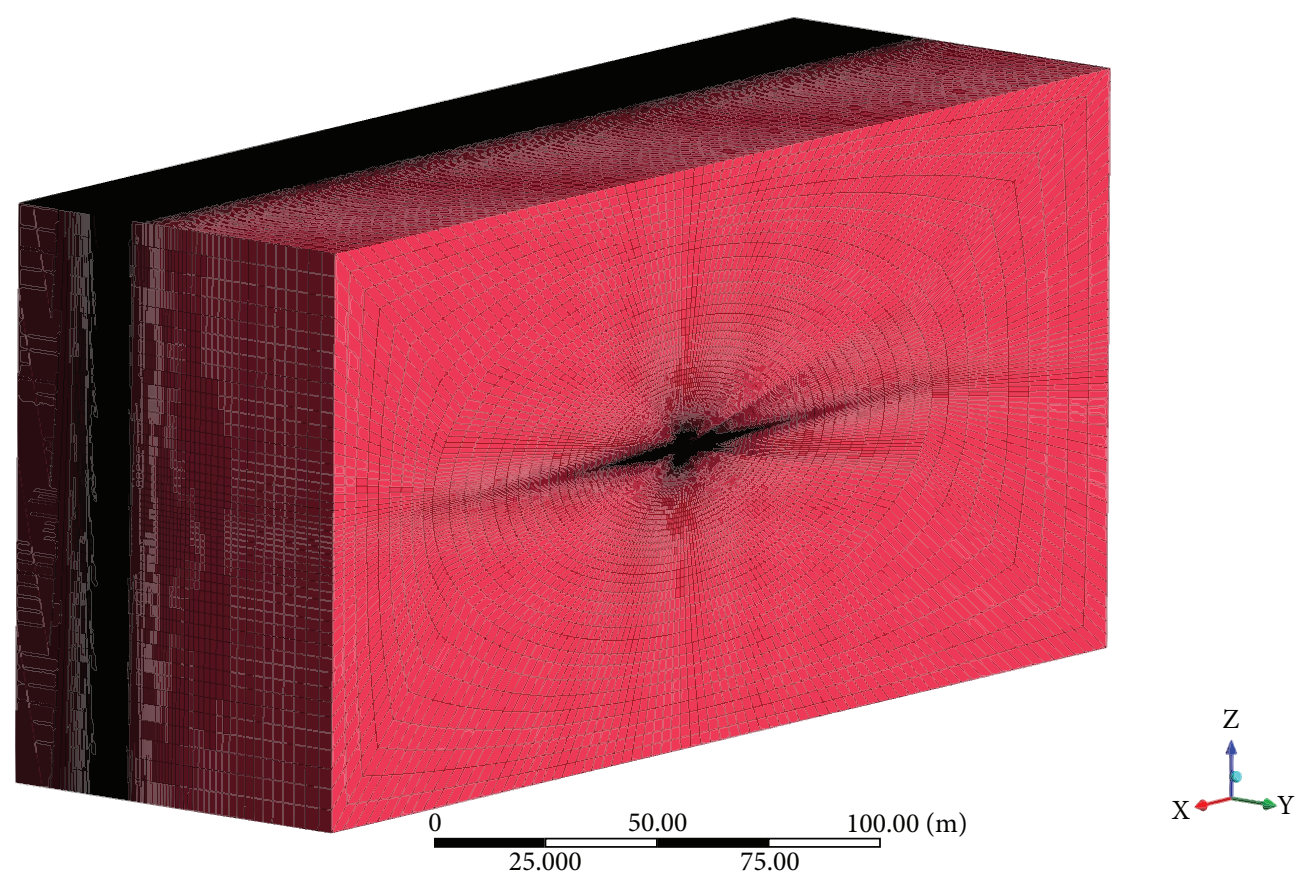

Figure 3: CFD mesh of fluid domain (curved wing).

the $k$-epsilon model with enhanced wall treatment was adopted as a turbulence model [21].

Comparing the supersonic zone around the two wings in Figures $7-11$, there is a notable difference in shape and dimension at the outer zone of the wings. The results shown refer to an altitude of $10,000 \mathrm{~m}$, a Mach number of 0.85 , and a lift coefficient $C_{L}=0.4$ : i.e., typical values for cruise flight conditions of a transport aircraft.

The numerical results of the CFD analyses are summarized in Table 1. Figures 12 and 13 compare the wing polar 


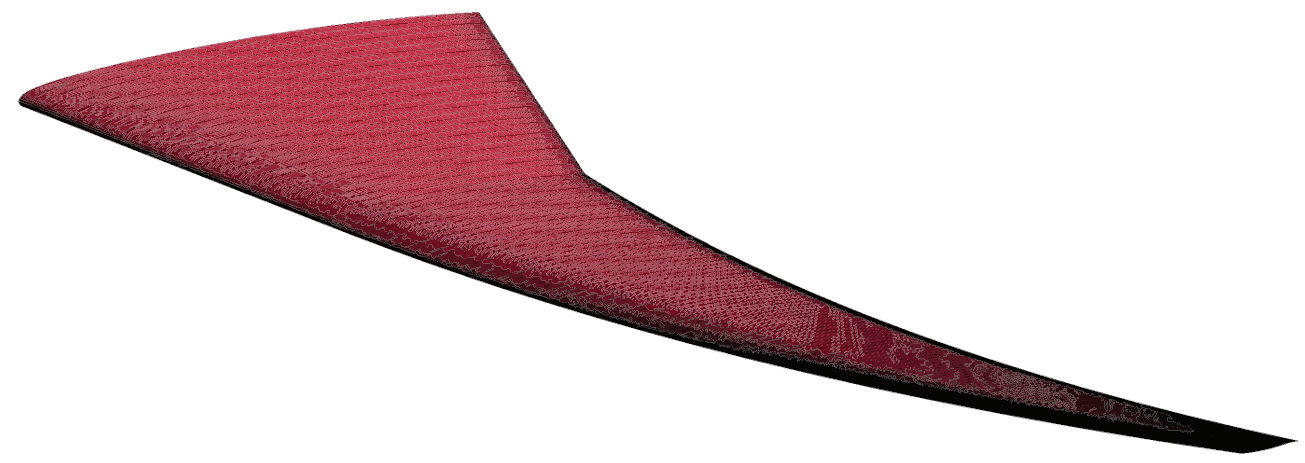

FIGURE 4: Curved-wing surface mesh.

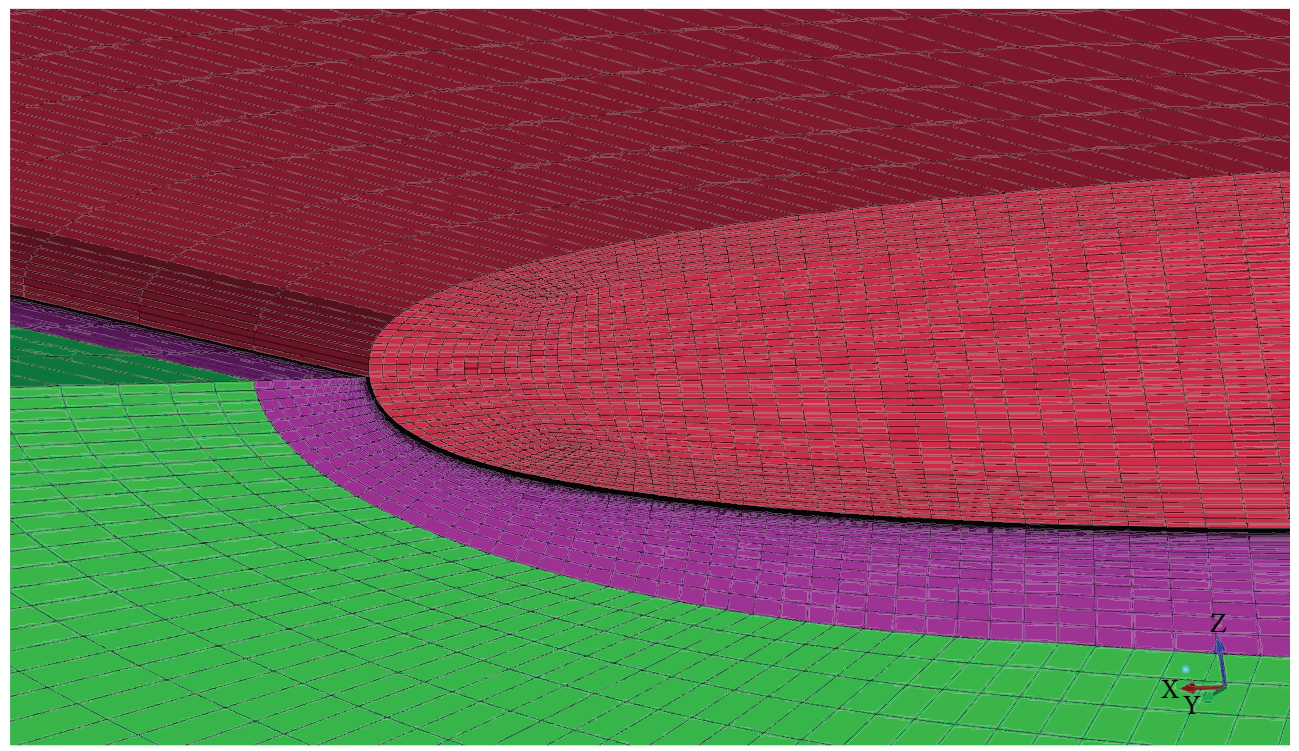

FIgURE 5: CFD mesh of curved wing (wing tip detail).

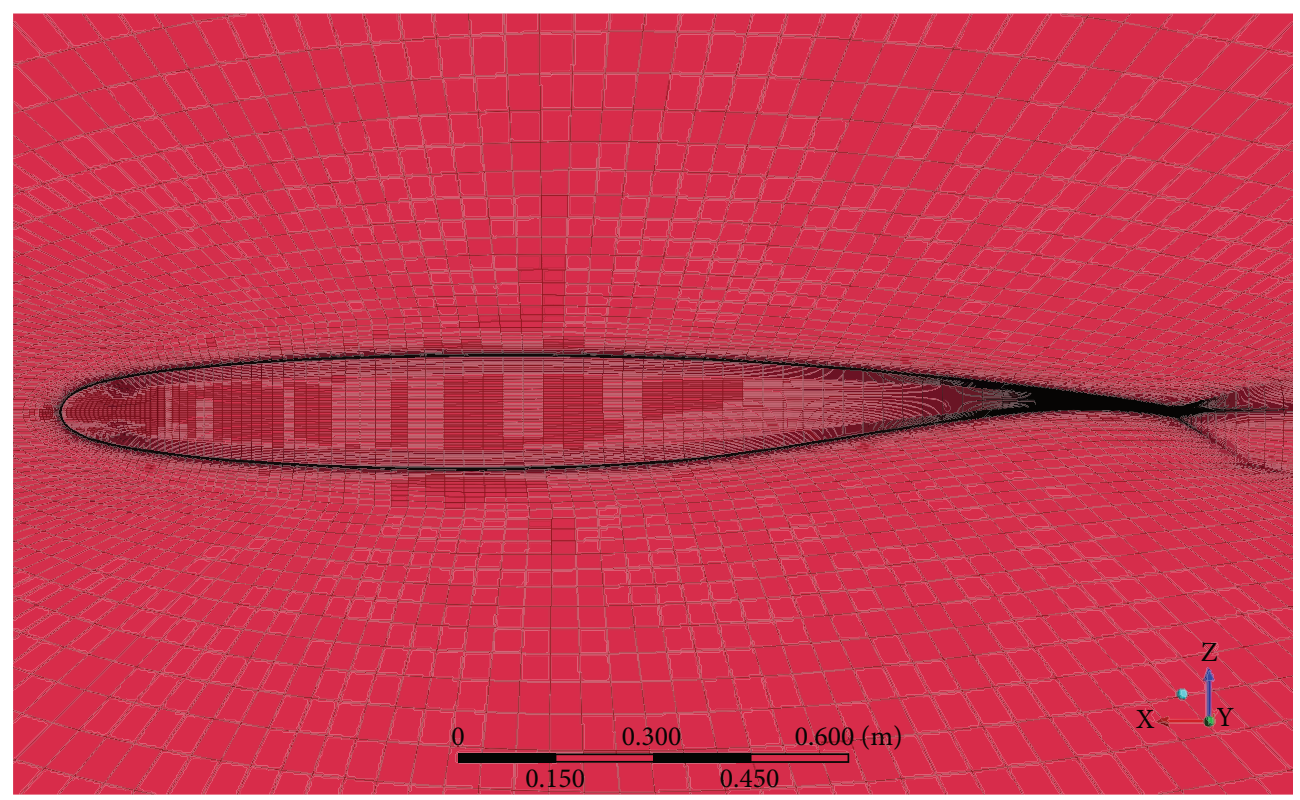

FIGURE 6: Side view of curved-wing domain mesh. 


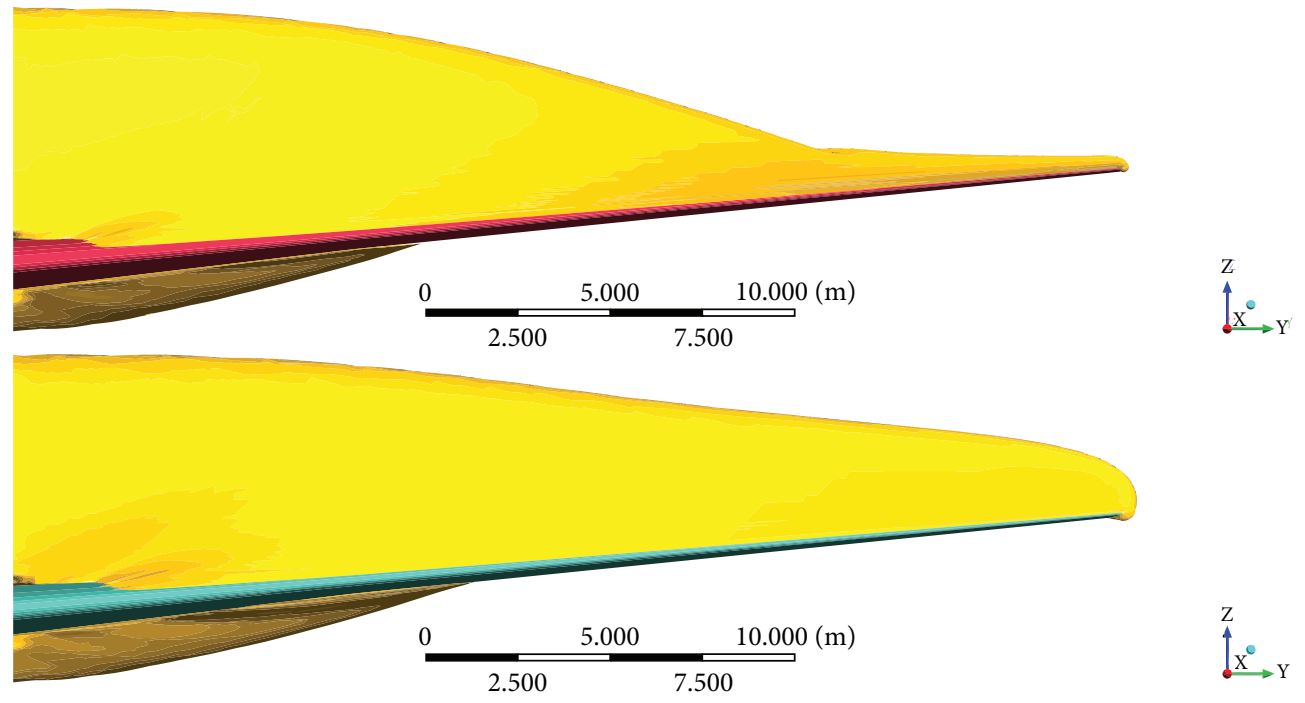

Figure 7: Supersonic regions (front view: $h=10,000 \mathrm{~m}, C_{L}=0.4, M=0.85$; top image: curved wing, bottom image: swept wing).
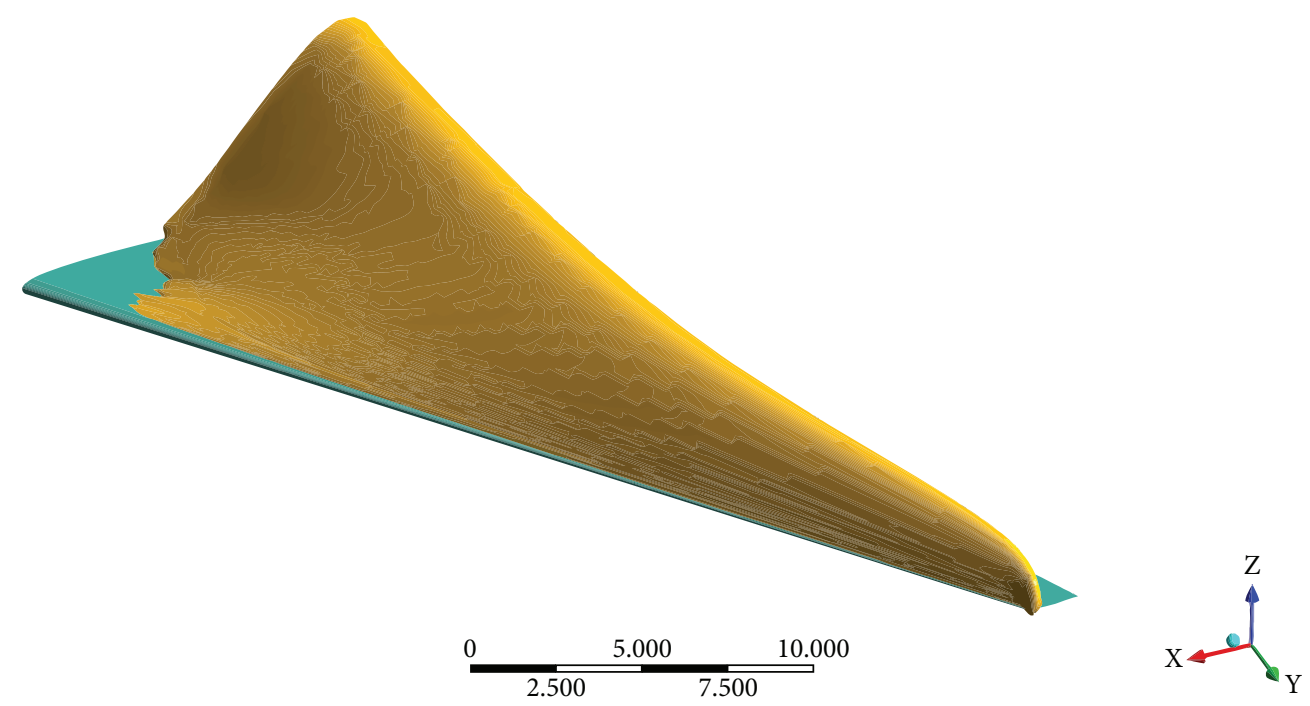

FiguRE 8: Supersonic region (swept wing: isoview front).

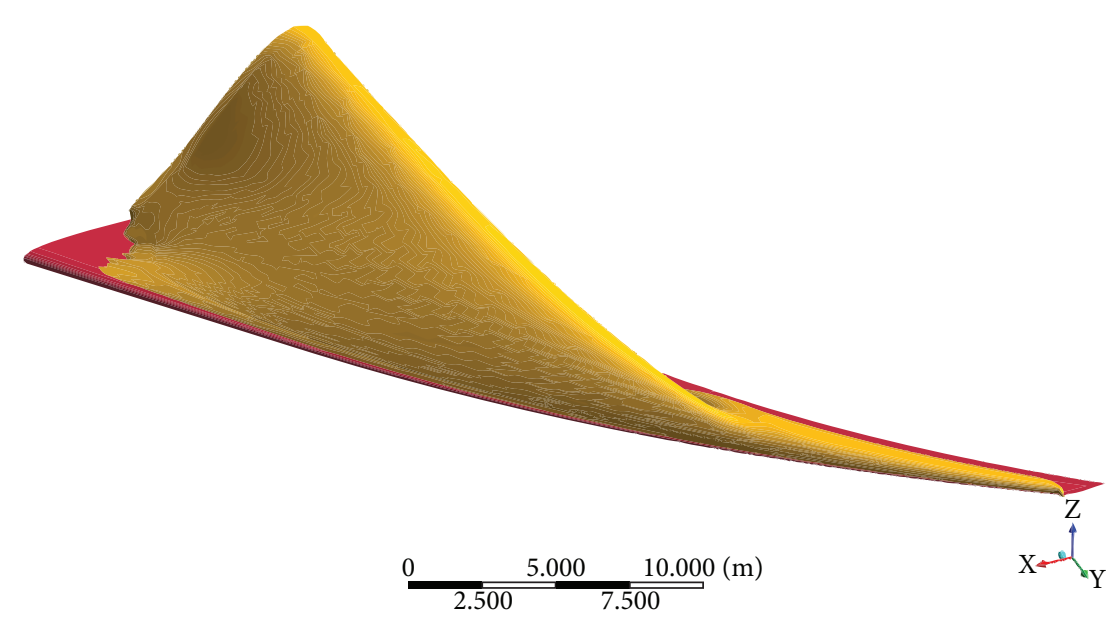

FIGURE 9: Supersonic region (curved wing: isoview front). 


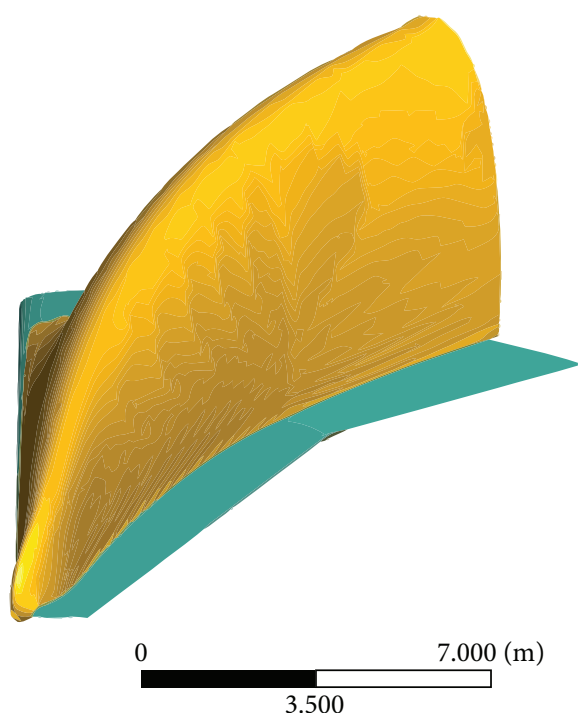

FIGURE 10: Supersonic region (swept wing: isoview rear).

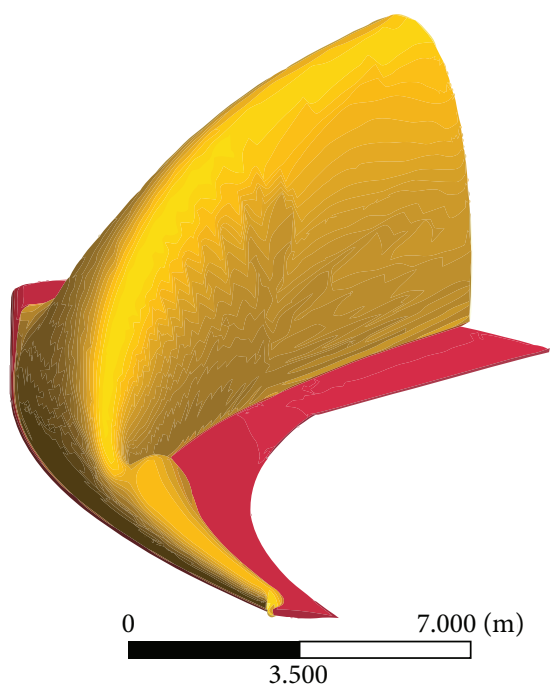

FIGURE 11: Supersonic region (curved wing: isoview rear).

curves and efficiencies, respectively. There is a clear improvement in the curved-wing efficiency: for $C_{L}=0.4$, a drag reduction of about $7.7 \%$ can be obtained (Table 2), and for the efficiency, an increase of about $8.3 \%$ can be estimated from Figure 13. The pressure component of the drag coefficients shows the most important difference (Table 2): in the transonic flow condition, the wave drag of a curved planform wing is strongly reduced. Similar results are discussed in [18]. There is a secondary effect in the induced drag component of the two wings. Figure 14 compares the distribution of the $x$ component of the velocity curl in the wake of two wings. On planes positioned at the same distance from the leading edge of the wing root profiles, the wake energy content is higher for the swept wing $\left(X_{P}\right.$ indicates the $x$ coordinate of each control plane in the reference system set for CFD analysis).
TABLE 1: CFD results for swept-wing and curved-wing models $\left(M=0.85, h=10,000 \mathrm{~m}\right.$, and $6.5 \times 10^{6}$ cells $)$.

\begin{tabular}{lccc}
\hline$\alpha(\mathrm{deg})$ & $C_{L}$ & $C_{D}$ & $C_{L} / C_{D}$ \\
\hline \multicolumn{4}{c}{ Swept wing } \\
-1 & 0.133 & 0.008179 & 16.31 \\
0 & 0.287 & 0.011252 & 25.53 \\
0.711 & 0.400 & 0.016168 & 24.74 \\
1 & 0.445 & 0.019127 & 23.40 \\
2 & 0.577 & 0.031609 & 18.27 \\
3 & 0.663 & 0.045850 & 14.47 \\
& \multicolumn{2}{c}{ Curved wing } \\
-1 & 0.120 & 0.007629 & 15.78 \\
0 & 0.252 & 0.009776 & 25.80 \\
1 & 0.386 & 0.014269 & 27.04 \\
1.106 & 0.400 & 0.014926 & 26.80 \\
2 & 0.518 & 0.022542 & 22.99 \\
3 & 0.631 & 0.037493 & 16.84 \\
\hline
\end{tabular}

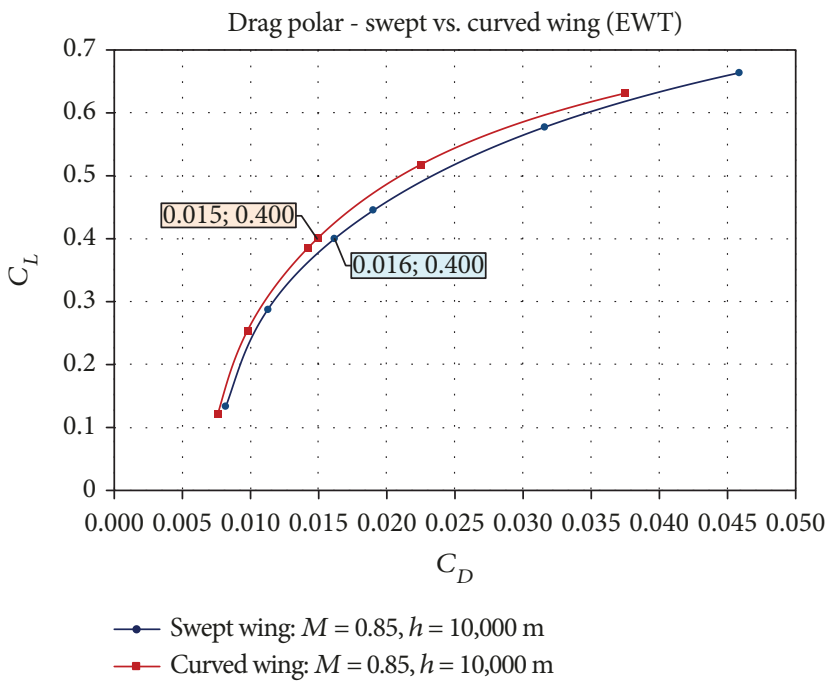

FIgURE 12: Drag polar curves $(M=0.85, h=10,000 \mathrm{~m})$.

On the basis of the results obtained, a preliminary estimation of the fuel consumption reduction was carried out following a standard procedure [57]. A simplified reference mission was considered for a wide-body long-range airliner. For a constant-altitude flight, with a constant cruise velocity, the following equation must be satisfied:

$$
\frac{d X}{d W}=-\frac{V}{c} \cdot \frac{1}{q \cdot S \cdot C_{D}}
$$

where $X$ is the distance travelled, $W$ is the weight of the aircraft (which changes during the flight), $V$ is the velocity of the aircraft, $c$ is the specific fuel consumption, $q$ is the dynamic pressure, $S$ is the reference wing area of the aircraft, and $C_{D}$ is the drag coefficient which changes according to the 


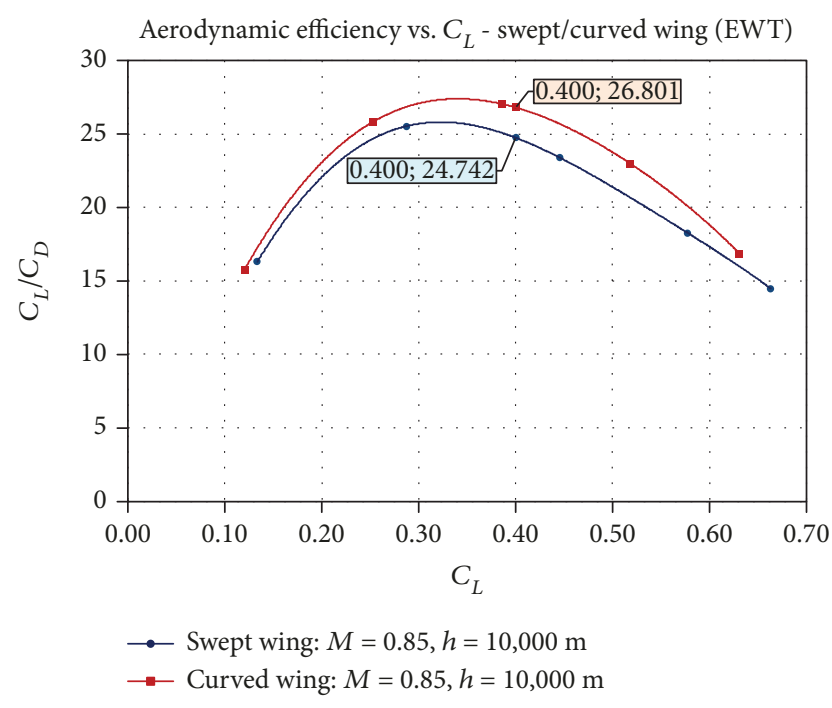

Figure 13: Efficiency of wings $(M=0.85, h=10,000 \mathrm{~m})$.

TABLE 2: Estimation of drag reduction $(M=0.85, h=10,000 \mathrm{~m}$, $C_{L}=0.4$, and $6.5 \times 10^{6}$ cells).

\begin{tabular}{cccc}
\hline$\alpha(\mathrm{deg})$ & $C_{L}$ & $C_{D}$ & $C_{L} / C_{D}$ \\
\hline \multirow{4}{*}{0.711} & \multicolumn{2}{c}{ Swept-wing model } \\
& 0.4 & 0.016168 & 24.74 \\
& & $C_{D \text { pressure }}$ & $C_{D \text { viscous }}$ \\
& & 0.01189 & 0.00427 \\
& \multicolumn{4}{c}{ Curved-wing model } \\
1.106 & 0.4 & \\
& & $C_{D \text { pressure }}$ & 26.80 \\
& & 0.01068 & $C_{D \text { viscous }}$ \\
& & $\Delta C_{D} / C_{D}$ & 0.00425 \\
& & $7.68 \%$ & \\
\hline
\end{tabular}

variation of aircraft trim conditions (i.e., $C_{D}$ varies according to the polar curve law).

By interpolating, in a first approximation, the polar curves of wing models with two distinct polynomials, equation (1) can be integrated step by step.

Table 3 summarizes the results obtained for $X=6482 \mathrm{~km}$ $(3500 \mathrm{~nm})$, initial weight of the airplane, $W_{0}=210,000 \mathrm{kgf}$, reference surface $S=379 \mathrm{~m}^{2}$, cruise altitude $h=10,000 \mathrm{~m}$, Mach number $M=0.85$, and specific fuel consumption $c=$ $0.545 \mathrm{~h}^{-1}$. According to these results, the fuel saving as a percentage of the fuel consumed by the swept wing is:

$$
\frac{\Delta W_{F}}{W_{F}}=\frac{W_{F \text { swept }}-W_{F \text { curved }}}{W_{F \text { swept }}}=6.64 \% \text {. }
$$

As expected, this value lies between the drag coefficient percentage reduction related to the beginning of the cruise $(8.18 \%)$ and the reduction related to its end (5.14\%). Although this example overestimates the fuel saving due to the simplifying assumption that the airplane drag polar is only represented by the rigid clean wing polar, it highlights that fuel consumption can be reduced significantly.

In order to perform the FSI analyses using coarser meshes, to optimize both time and computational resources, a sensitivity analysis was carried out by taking into account rigid CFD results. For the swept-wing model, the analysed meshes have $2.5 \times 10^{5}, 4 \times 10^{5}, 5.5 \times 10^{6}$, and $6.5 \times 10^{6}$ nodes, respectively. The results relate to an angle of attack $\alpha=0.76^{\circ}, M=0.85$, and $h=10,000 \mathrm{~m}$ (corresponding to an expected value for the lift coefficient $C_{L}=0.4$ ). In the case of the curved-wing model, the analysed meshes have $4 \times 10^{5}$ and $6.5 \times 10^{6}$ nodes, respectively. In this latter case, to obtain a $C_{L}=0.4$, an angle of attack $\alpha=1.15^{\circ}$ and similar values for Mach number and altitude were used.

The lift coefficient and drag coefficient of the swept wing as a function of the number of nodes (or cells) are represented in Figures 15 and 16, respectively. For the curved wing, the relevant coefficients are represented in Figures 17 and 18, respectively. For the finest meshes, both wall function and enhanced wall treatment were used. The results in terms of $C_{L}$ and $C_{D}$ are very close to each other, as highlighted by Figures 15-18.

On the basis of these results, an estimation of errors can be made for the meshes made up of 400,000 cells taking the meshes made up of 6,500,000 cells as a reference.

For the $C_{L}$ and $C_{D}$ of the swept-wing model, we have (wall function method):

$$
\begin{aligned}
& \frac{\Delta C_{L \text { swept }}}{C_{L \text { swept }}}=\frac{0.4-0.361}{0.4}=9.75 \%, \\
& \frac{\Delta C_{D \text { swept }}}{C_{D \text { swept }}}=\frac{0.0215-0.01698}{0.01698}=26.62 \%,
\end{aligned}
$$

while for the $C_{L}$ and $C_{D}$ of the curved-wing model, we have (wall function method):

$$
\begin{aligned}
& \frac{\Delta C_{L \text { curved }}}{C_{L \text { curved }}}=\frac{0.4-0.364}{0.4}=9.0 \%, \\
& \frac{\Delta C_{D \text { curved }}}{C_{D \text { curved }}}=\frac{0.0199-0.01571}{0.01571}=23.67 \% .
\end{aligned}
$$

As can be seen, the estimated errors for $C_{L}$ are less than $10 \%$, while the errors for the $C_{D}$ coefficient are more significant, at about $27 \%$. On the other hand, very similar numerical errors affect both swept and curved models. Based on these results, coupled dynamic analyses (FSI) were executed by adopting the meshes made up of 400,000 cells, also considering that the most important component of aeroelastic forces is produced by the pressure distribution and then by the lift effects.

\section{Results of the Aeroelastic Analyses}

This section focuses on the dynamic aeroelastic problem of the swept wing and the curved wing by means of 2-way FSI analyses, using CFD models made up of 400,000 cells 


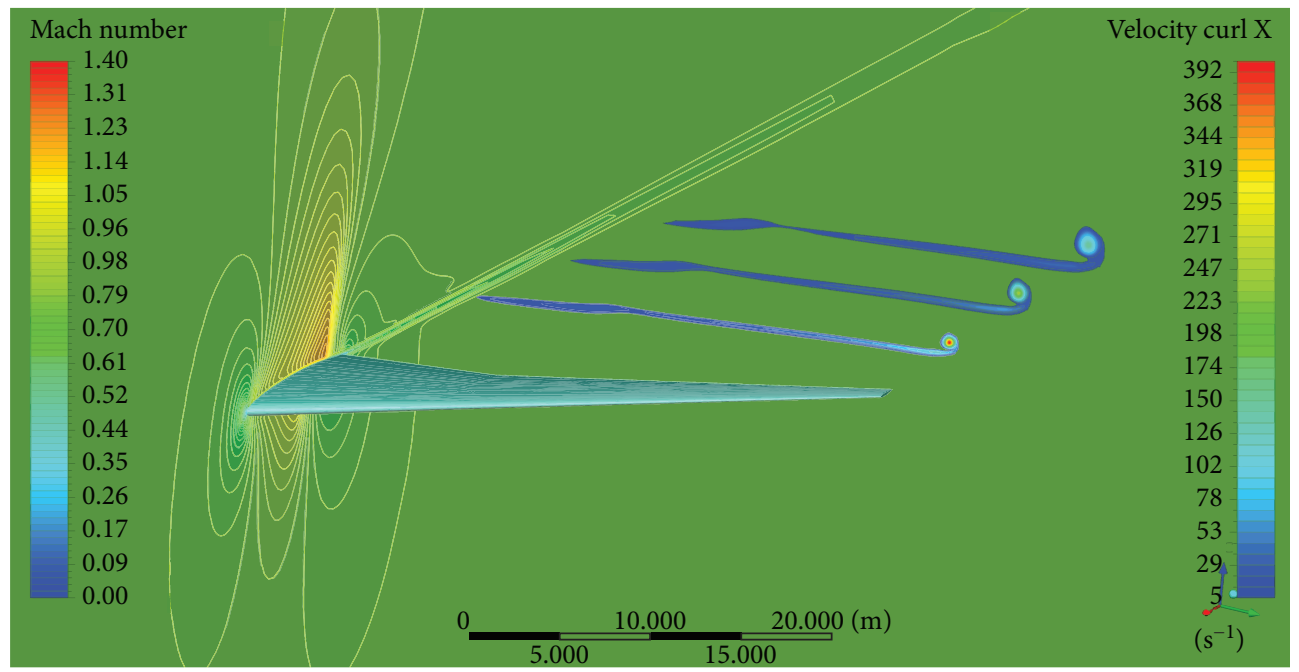

(a) Swept wing

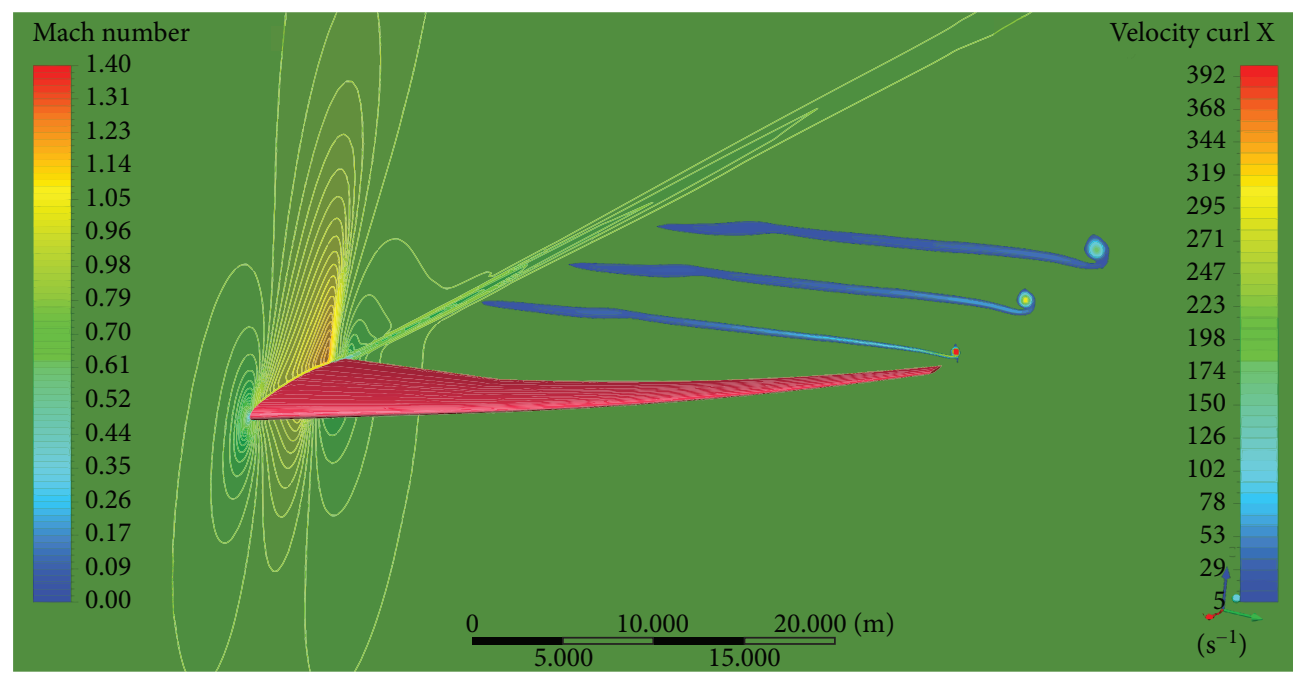

(b) Curved wing

Figure 14: Axial component of velocity curl on three control planes in the wake $\left(X_{P}=-29 \mathrm{~m},-39 \mathrm{~m},-40 \mathrm{~m} ; h=10,000 \mathrm{~m}, C_{L}=0.4, M=0.85\right)$.

TABLE 3: Estimation of fuel saving for a long-range mission.

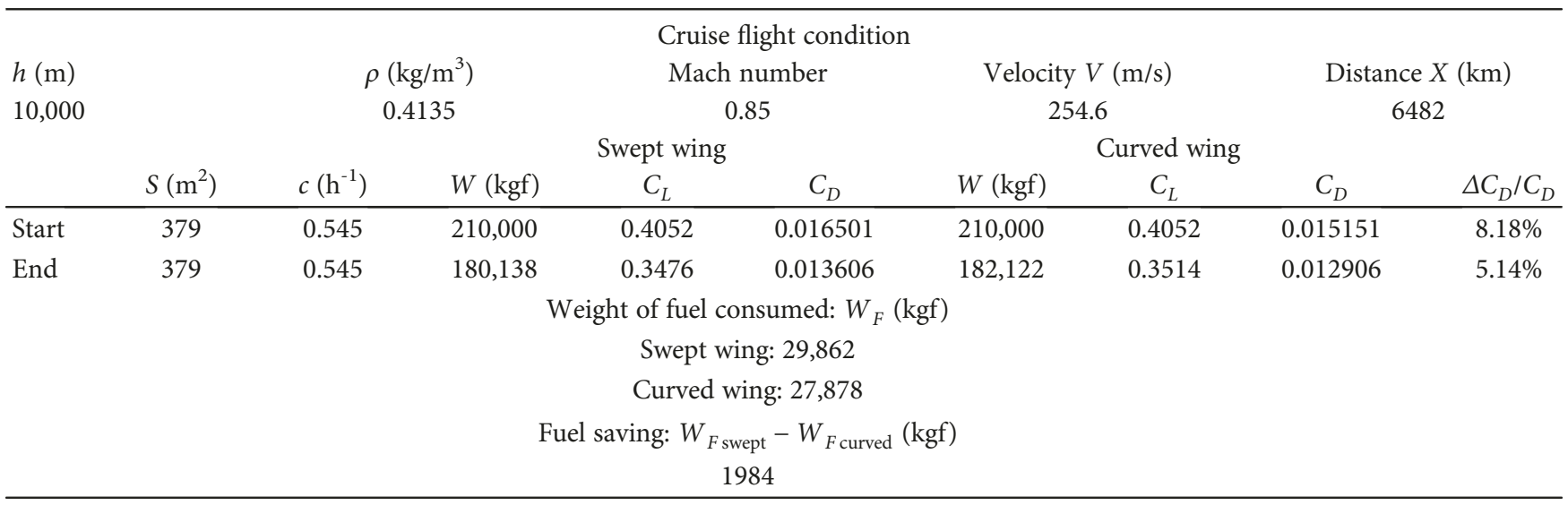




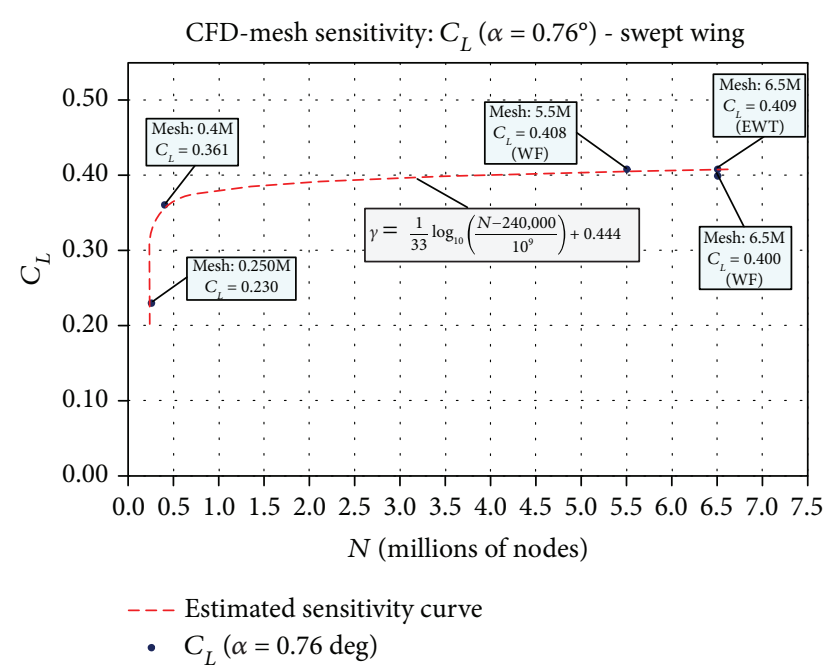

Figure 15: CFD mesh sensitivity $-C_{L}$ of swept wing.

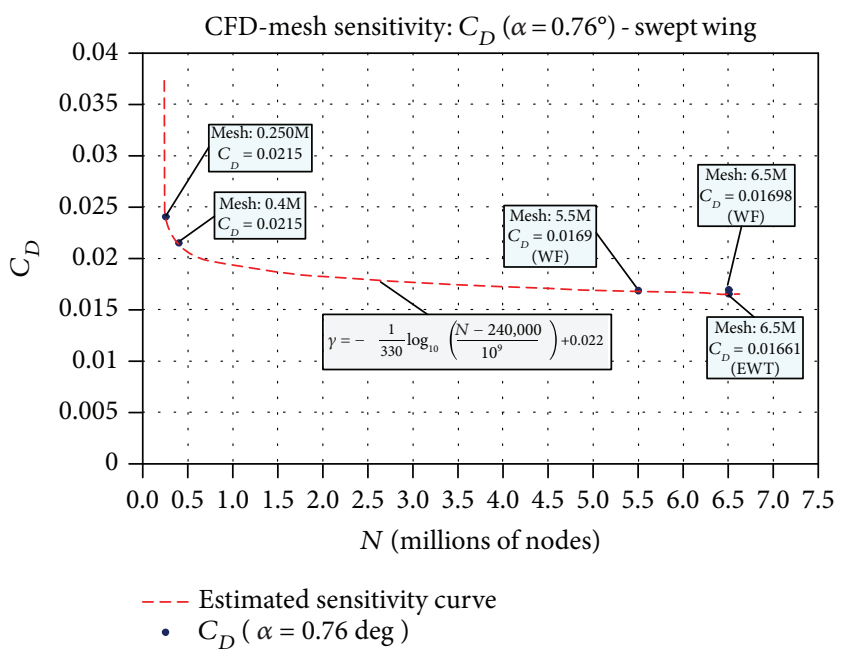

Figure 16: CFD mesh sensitivity $-C_{D}$ of swept wing.

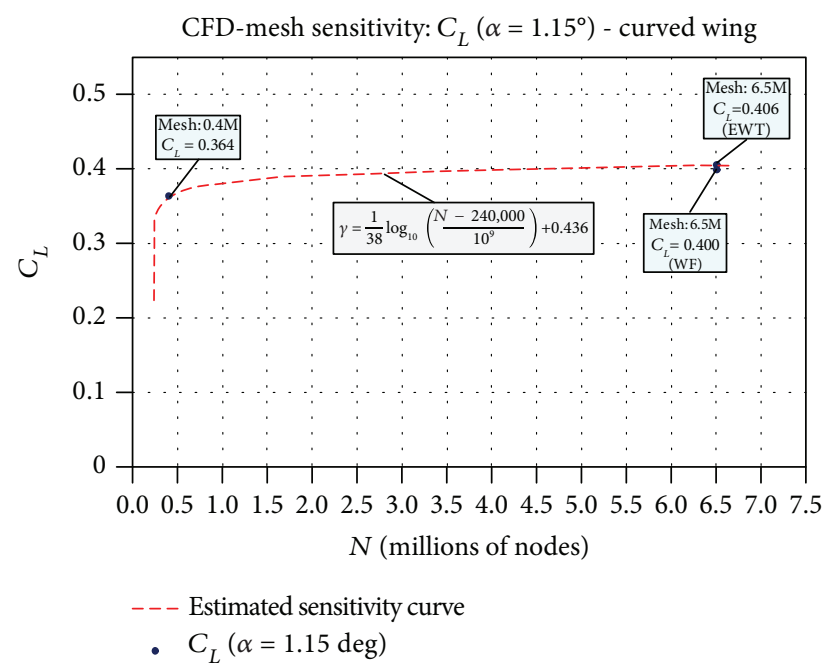

Figure 17: CFD mesh sensitivity- $C_{L}$ of curved wing.

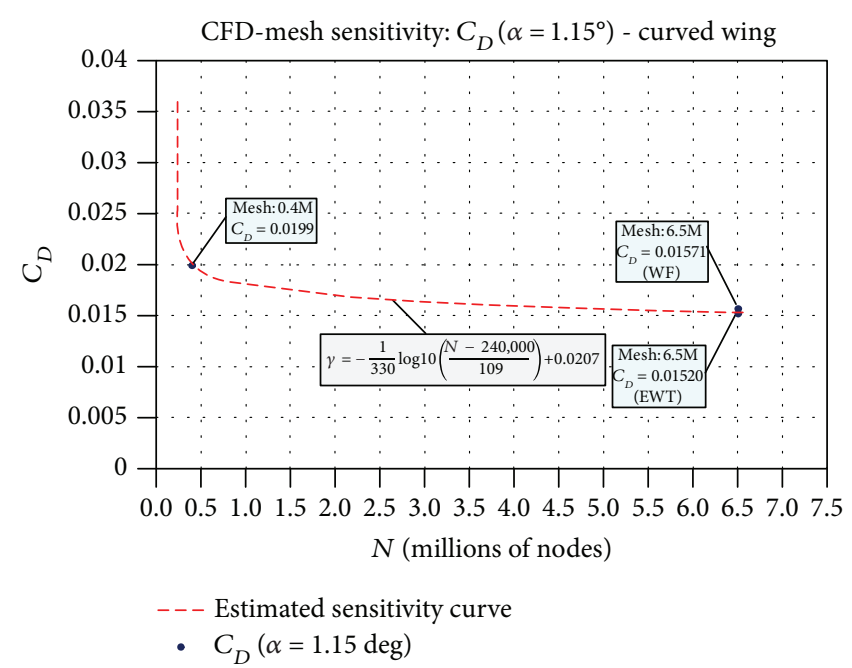

Figure 18: CFD mesh sensitivity $-C_{D}$ of curved wing.

( $400 \mathrm{~K})$. The characteristics of the flow field were set following the same method adopted for the rigid analyses.

FSI applications entail coupling fluid dynamics with structure mechanics. The equations governing the flow and the displacement of the structure are solved separately, with two distinct solvers. The FSI analysis performed in this work is a transient time domain-based analysis, where the problem is solved in a sequence of small time intervals in both the CFD solver and the finite element solver. During the FSI simulation, the System Coupling module coordinates the solution process between fluent and mechanical APDL solvers [21].

With reference to Figure 19, the first step is to assign the Fluid-Solid Interface flag to all of the faces that are in contact with the fluid. This boundary condition enables System Coupling to recognize the structural mesh region where the data transfer will occur.

The altitudes considered are the sea level and cruise flight conditions $(10,000 \mathrm{~m})$, as discussed in [20].

The wing models were analysed with angles of attack giving a similar lift coefficient obtained with rigid analyses. As a reference, the following were assumed: Mach $=0.85$ and $h$ $=10,000 \mathrm{~m}$ giving $C_{L}=0.36$ for both wings ( $400 \mathrm{~K}$ meshes), as shown in Figures 15 and 17. To guarantee the same value of rigid $C_{L}$, different angles of attack were set for swept and curved wings. These angles of attack were used for all the FSI analyses in both subsonic and transonic regimes.

At the beginning of this research, we expected a classical flutter instability for both wing models. Thus, fictitious moments of inertia (symbolically represented at the wing tip zone in Figure 19) were added near the tip of the two wings in order to reduce the natural torsional frequency of vibration down to a more realistic value and to promote the interaction of bending and torsion modes with the aerodynamic loads.

Two separate cases were studied with different inertia distributions: Case 1 and Case 2 [20]. In addition, to highlight the effects of the numerical solver approaches on the aeroelastic responses of wings, both pressure-based (PB) and 


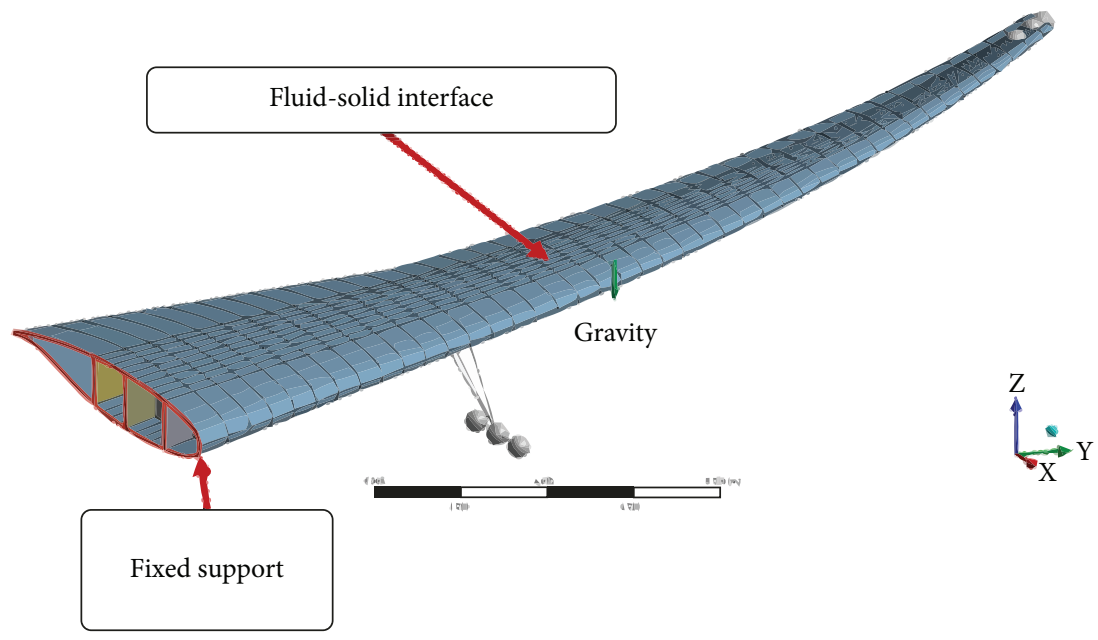

FIGURE 19: FEM boundary conditions.

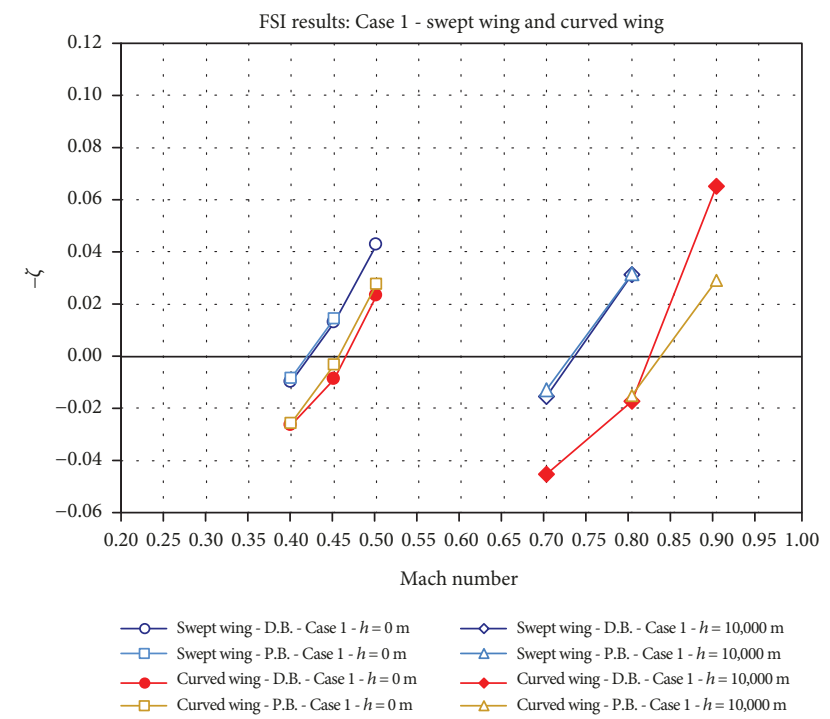

Figure 20: Damping vs. Mach (Case 1): density-based and pressure-based results.

density-based (DB) options [21] were used for the FSI comparative analyses.

3.1. Case 1: Heavy Fictitious Moments of Inertia. At sea level and at the simulated cruise altitude, both wings reached a classical flutter instability (Figure 20). At cruise altitude, for the swept-wing model there was a fully subsonic flow condition. For the curved-wing model, a fully transonic flow was established. As can be seen in Figure 20, at sea level, the available solvers (density based or pressure based) provide similar estimations for the overall damping parameter, while at cruise altitude for the curved-wing model a difference arises in the unstable regime. In any case, the flutter speed of the curved wing is higher than the swept wing. The aeroelastic behaviour of the two wings above the instability conditions at sea level and at cruise altitude can be better understood by observing the following animation files: Swept-Case_1Sea_Level- $M=0.45$, Curved-Case_1-Sea_Level- $M=0.5$,

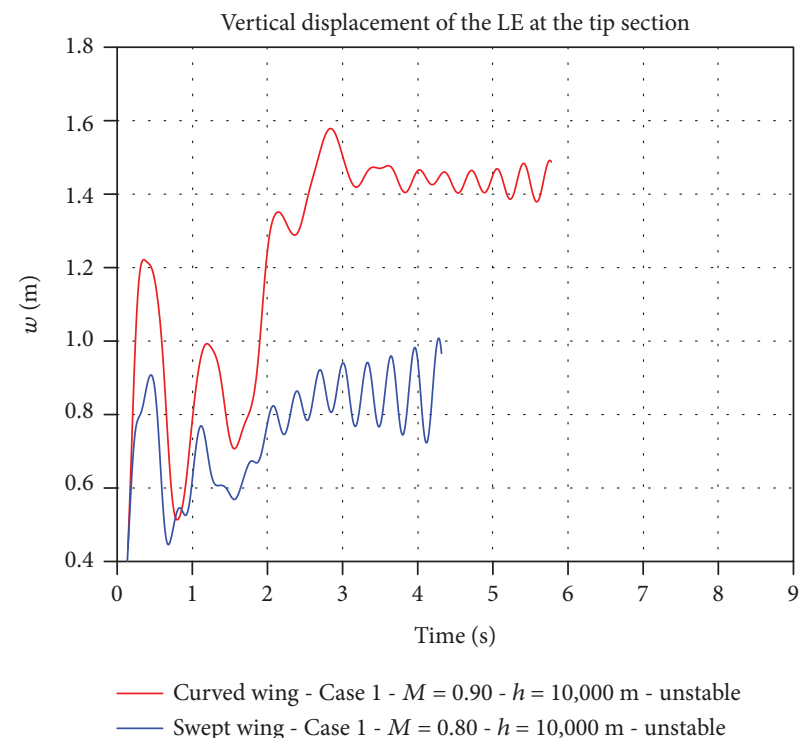

FIgURE 21: FSI DB-displacement histories at the leading edge of wing tips (Case $1[20]$ ).

Swept-Case_1-Cruise- $M=0.8$, and Curved-Case_1Cruise $-M=0.9$; all these files refer to density-based results.

Bending and torsion of the wings are involved in these forms of instability, and the amplitude of unstable oscillations increases rapidly above the flutter speed (Figure 21).

For the cruise altitude, an estimation of the displacement LCOs for the wing tip leading edge of the two wings is shown in Figures 22 and 23.

According to the criteria discussed in $[26,27]$, these figures show that the curved-wing postcritical aeroelastic response is probably affected by the nonlinearities due to the transonic flow. In this case, the same change in the Mach number causes the amplitude of displacement LCOs to grow less rapidly with respect to the swept wing (compare Figure 23 with Figure 22).

Figure 24 compares the LCOs computed for the lift coefficients of swept and curved wings in the postcritical 


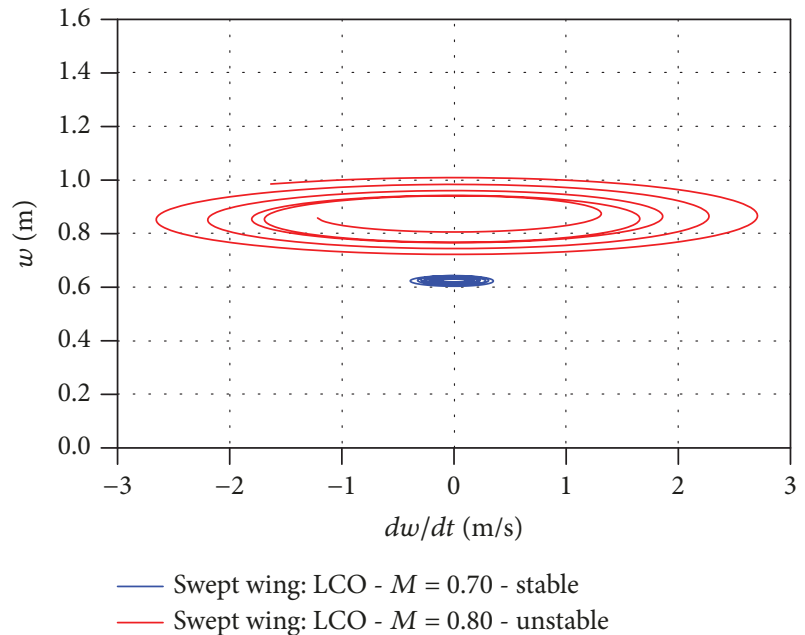

FIGURE 22: FSI DB-estimation of swept-wing tip displacement LCOs (Case 1-cruise [20]).

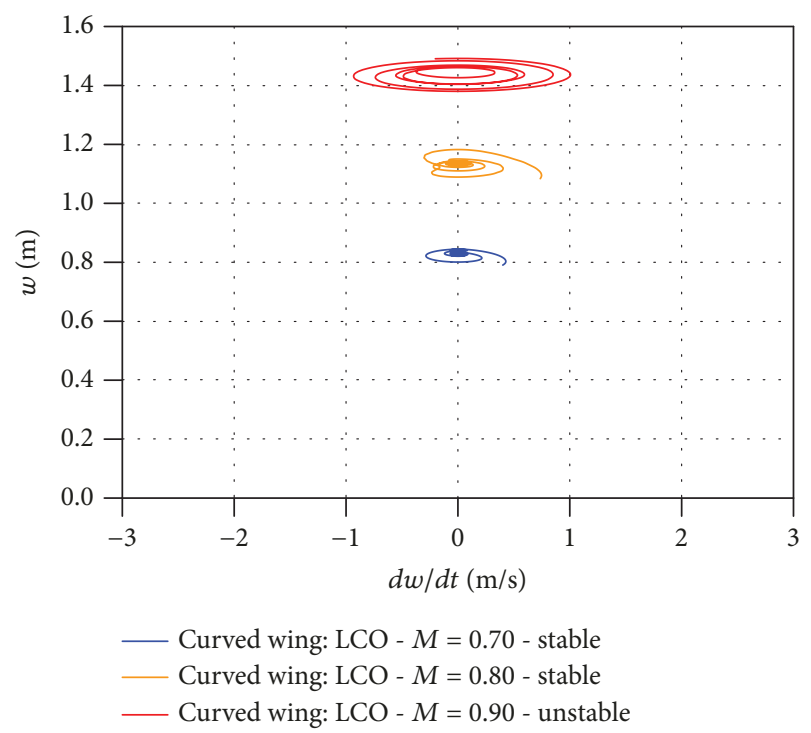

Figure 23: FSI DB-estimation of curved-wing tip displacement LCOs (Case 1-cruise [20]).

conditions. Although the LCOs are not fully stable, their amplitude differences confirm that the compressibility of fluid has different effects on the two wings.

Finally, for the same postcritical conditions, Figure 25 compares the LCOs computed for the powers of fluid obtained by combining the aerodynamic force vectors acting on the wing models and the velocity vectors of the surface's nodes. For the swept wing, the rate of power growth shows that the physics of a classical subsonic flutter phenomenon is involved, while a slightly different physical situation can be observed for the curved wing.

3.2. Case 2: Lighter Fictitious Moments of Inertia. To force the role of transonic flow phenomena, we applied lighter moments of inertia at the tip zones of the wing models. The

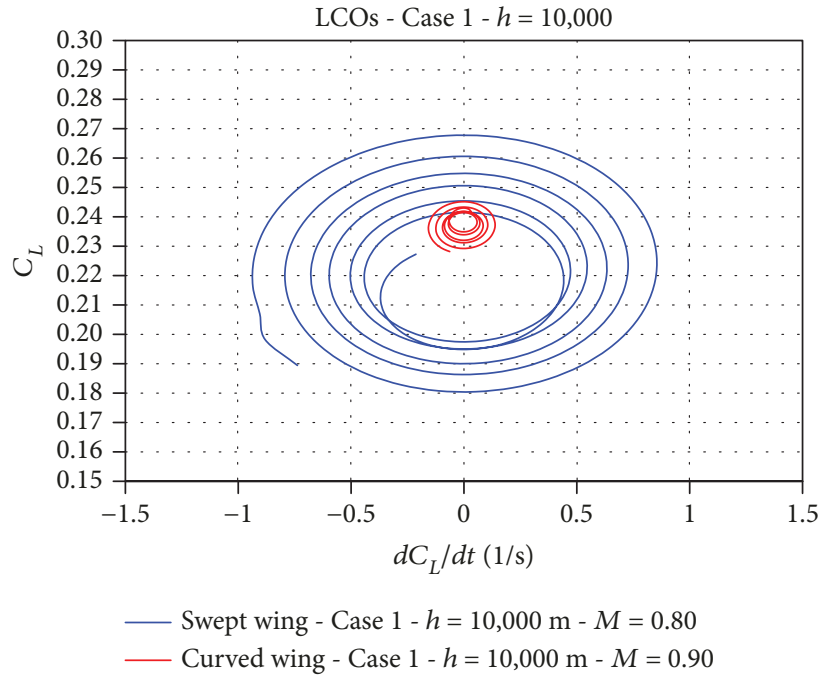

Figure 24: FSI DB-estimation of lift coefficient LCOs (Case 1).

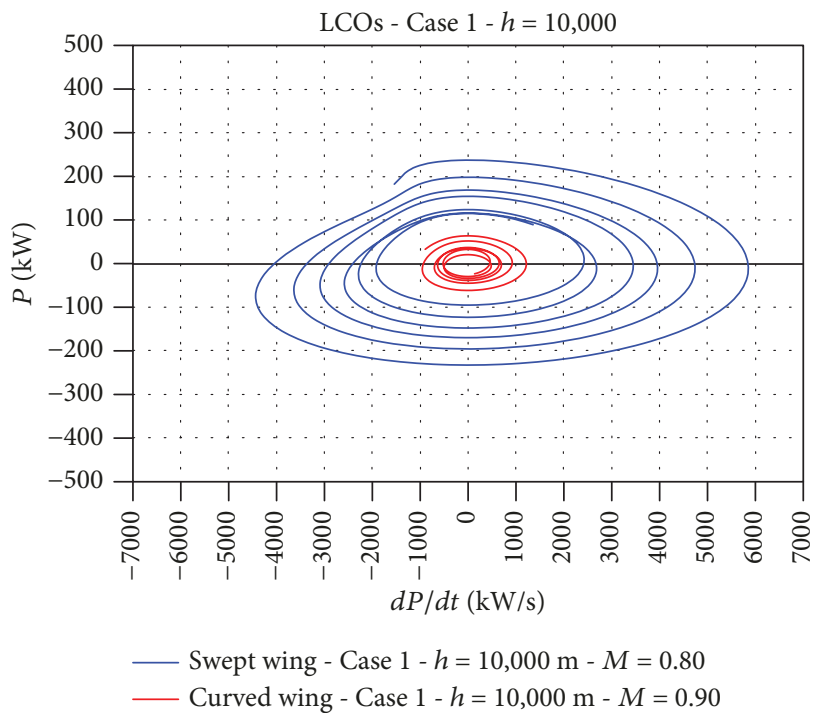

FIGURE 25: FSI DB—estimation of fluid power LCOs (Case 1).

parameters of Case 2 are summarized in [20]. In this case, only cruise altitude conditions were simulated. To confirm the hypothesis discussed in [20], i.e., the physical behaviour (approaching instability) of two wings, additional analyses were performed close to the stability margin of the two wings. Figure 26 shows the graph of damping parameter vs. Mach number at cruise altitude. Case 2 data were enriched with new analyses, and new results were added with respect to our previous work [20].

The aeroelastic conditions examined refer to the angles of attack corresponding to the lift coefficient $C_{L}=0.36$ obtained with rigid CFD analyses (as summarized in Figures 15 and 17 for the swept wing and curved wing, respectively). Taking into account the elasticity of the wing models, the actual value of $C_{L}$ obviously changes for both wings (it tends to go down). In the case of the swept wing, it was observed that for a fixed angle of attack, say $\alpha=0.76^{\circ}$, above the instability 


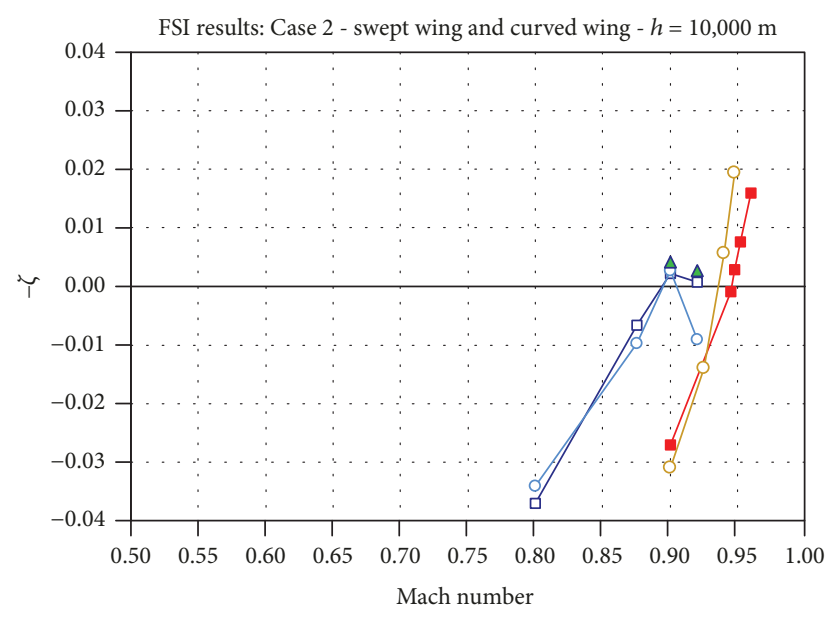

\begin{abstract}
$\longrightarrow$ - Swept wing - DB - Case $2-h=10,000 \mathrm{~m}-$ alfa $=0.76 \mathrm{deg}$
$-0-$ Swept wing - PB - Case $2-h=10,000 \mathrm{~m}-$ alfa $=0.76 \mathrm{deg}$

$\Delta \quad$ Swept wing - DB - Case $2-h=10,000 \mathrm{~m}-$ alfa $=0.977 \mathrm{deg}$

$\rightarrow$ Curved wing - DB - Case $2-h=10,000 \mathrm{~m}$ - alfa $=1.15 \mathrm{deg}$

$\multimap-$ Curved wing - PB - Case $2-h=10,000 \mathrm{~m}-$ alfa $=1.15 \mathrm{deg}$
\end{abstract}

FIgURE 26: Damping vs. Mach (cruise: Case 2).

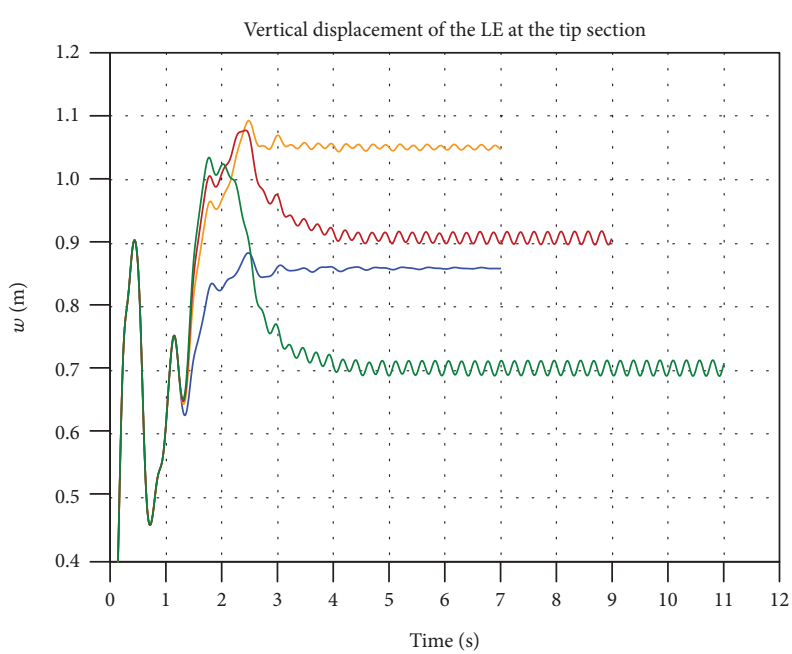

Swept wing - Case $2-M=0.800$ - alfa $=0.760 \mathrm{deg}-h=10,000 \mathrm{~m}$ - stable - Swept wing - Case $2-M=0.875-$ alfa $=0.760 \mathrm{deg}-h=10,000 \mathrm{~m}$ - stable Swept wing - Case $2-M=0.900$ - alfa $=0.760 \mathrm{deg}-h=10,000 \mathrm{~m}$ - unstable

Swept wing - Case $2-M=0.920$ - alfa $=0.760 \mathrm{deg}-h=10,000 \mathrm{~m}$ - unstable

Figure 27: FSI DB-displacement histories at the LE of the swept-wing tip (Case $2[20]$ ).

condition, the estimated damping parameter is very small, and by increasing the Mach number it tends to decrease. Adopting the pressure-based option, this parameter changes its sign again, indicating a stable dynamic condition. At the same time, for a fixed value of Mach number (say $M=0.90$ ), the damping parameter tends to increase if the angle of attack, and consequently $C_{L}$, is increased (Figure 26).

Figure 27 (density-based solution) shows the displacement histories of the leading edge of the swept-wing tip. In all unstable conditions, the amplitude of oscillations increases

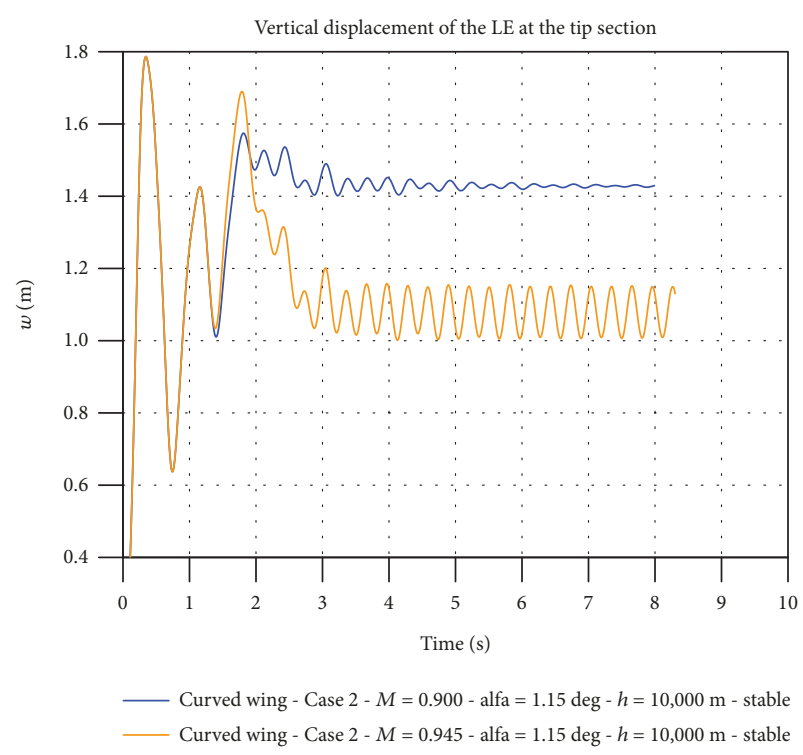

FIgURE 28: FSI DB-stable histories at the LE of the curved-wing tip (Case $2[20]$ ).

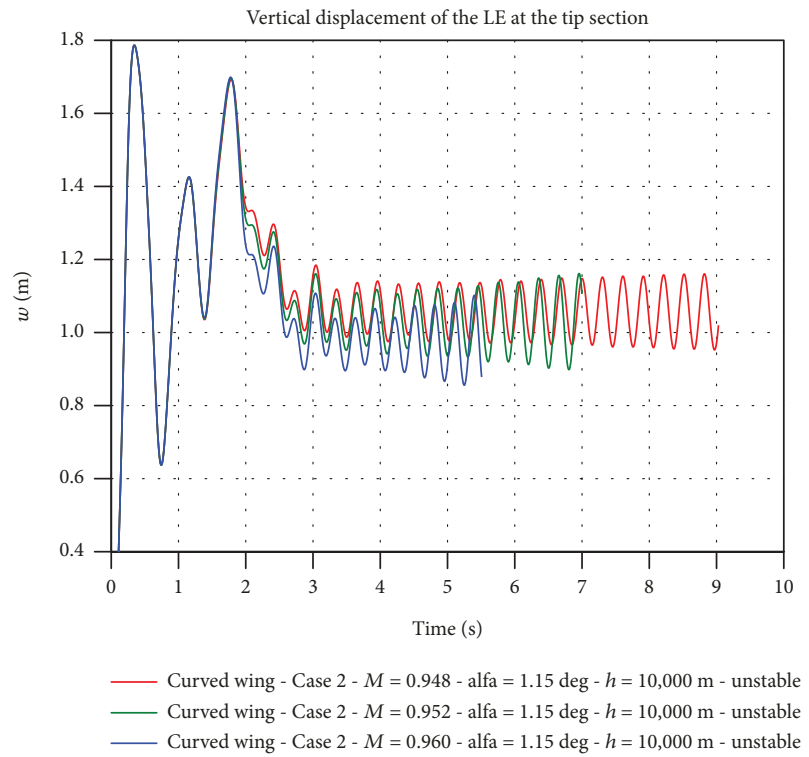

FIgURE 29: FSI DB-unstable histories at the LE of curved-wing tip (Case 2 [20]).

very slowly and the dynamic response of the swept wing depends on trim conditions.

In the case of the curved wing, the damping parameter increases monotonically as a function of the Mach number (Figure 26). The amplitudes of oscillations are now larger, and above the instability condition, they increase rapidly for small increments in Mach numbers (see Figures 28 and 29).

To highlight the differences in the behaviours of the two wing models, the LCOs of displacements were estimated as a function of the Mach number. Figures 30 and 31 show the results obtained for the swept wing and curved wing, 


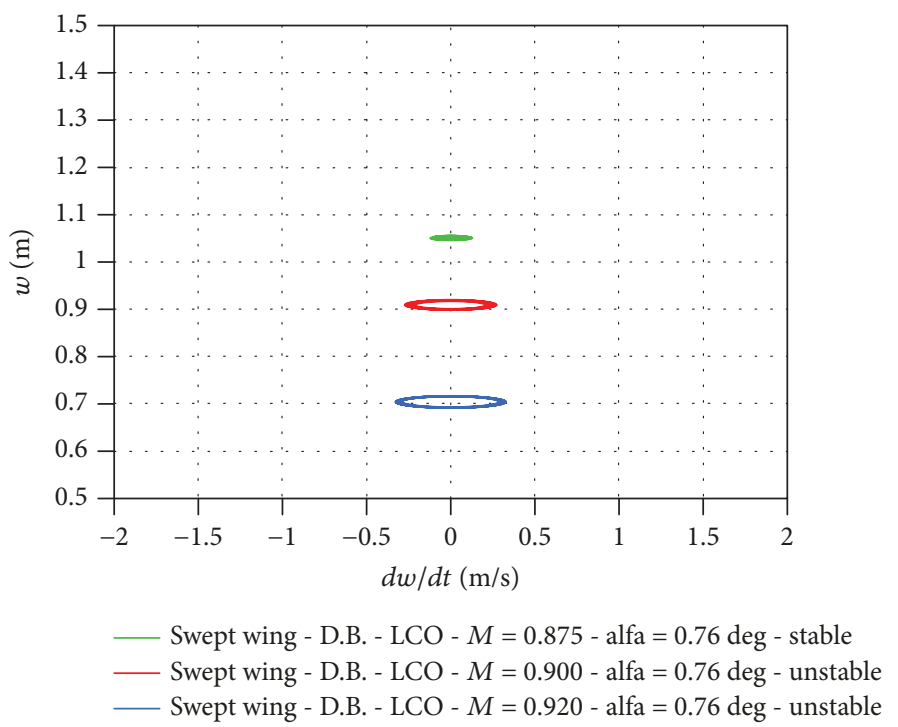

FIgURe 30: FSI analyses of the swept wing-Case 2 (cruise-tip displacement LCO_DB).

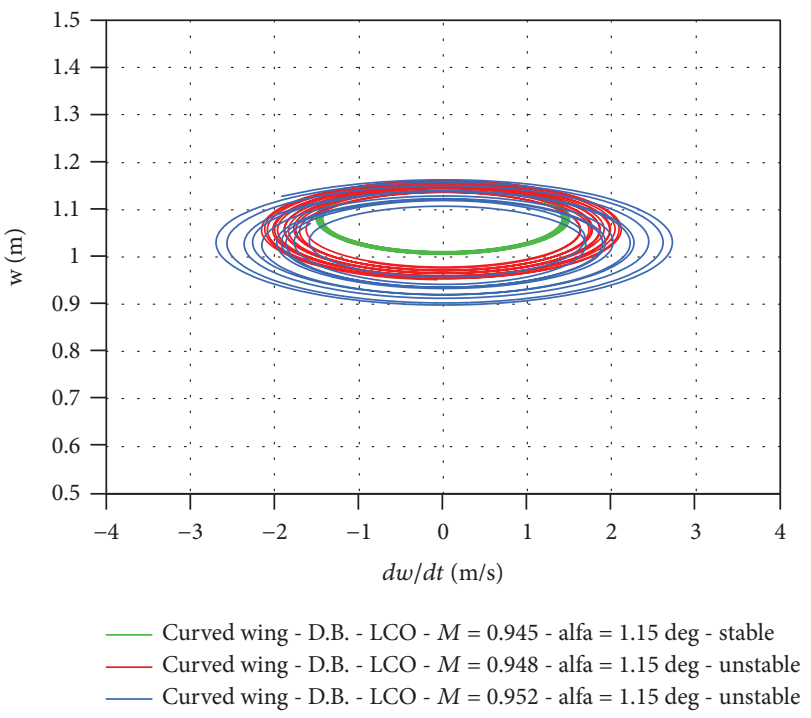

Figure 31: FSI analyses of the curved wing-Case 2 (cruise-tip displacement LCO-DB).

respectively. The evolution of LCOs for the swept wing follows the definition in [27] relating to the third type of dynamic instability observed for the BACT Model, i.e., a situation characterized by slowly diverging oscillations where a further increase in the Mach number enables a safe condition to be recovered, so that there is a dynamic equilibrium condition with small and constant amplitude oscillations (LCOs).

In this case, the aeroelastic response corresponds to a value of the overall damping parameter close to zero (as obtained with the density-based solver) or it may correspond to a fully stable dynamic equilibrium (as obtained with the pressure-based solver) (see Figure 26). Figure 30 shows that for the swept wing, an increase in the Mach number leads to a moderate increase in the slowly diverging oscillations,

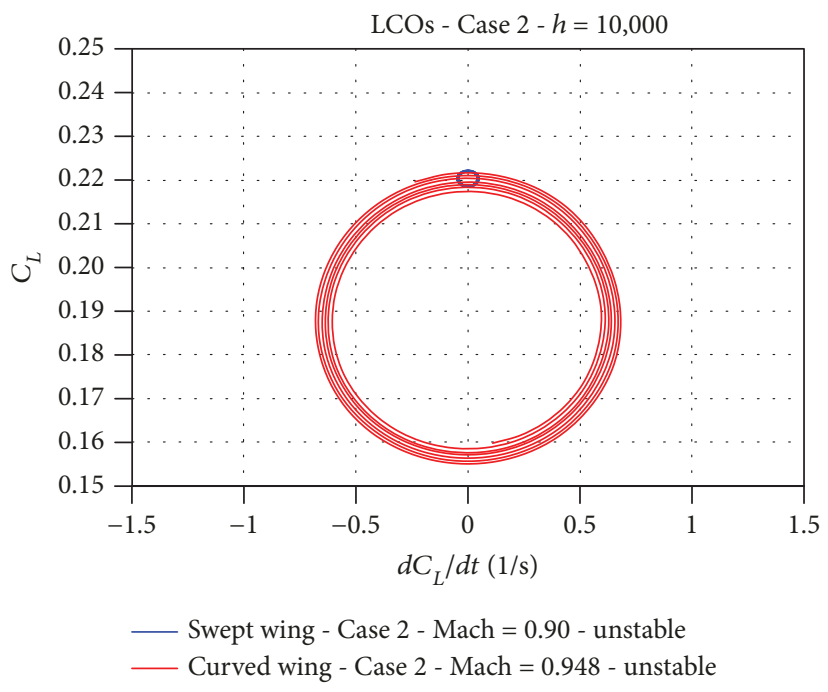

FIgURe 32: FSI analysis-estimation of lift coefficient LCOs (Case 2)-density based.

highlighting the strong nonlinear effects due to the transonic aerodynamic field.

On the other hand, the results obtained for the curved wing highlight that, the increase in LCO amplitude with a change in Mach number is rapid (Figure 31): i.e., classical flutter occurs according to the definition in [27]. In this case, the nonlinear effects of the transonic flow do not directly control the instability phenomenon.

As in the cruise condition for Case 1, Figure 32 compares LCOs computed for lift coefficients of swept and curved wings in the postcritical regime of Case 2. The conditions Mach $=0.90$ for the swept wing and Mach $=0.948$ for the curved wing, which correspond to almost similar damping parameters, were compared. The amplitude differences in LCOs confirm that the compressibility of fluid has different 


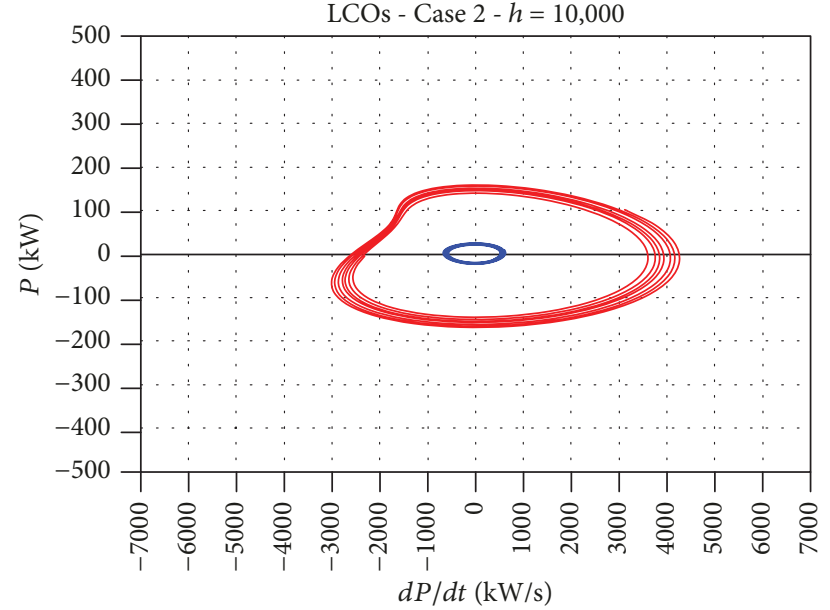

- Swept wing - Case $2-$ Mach $=0.90$

- Curved wing - Case 2 - Mach $=0.948$

FIGURE 33: FSI analysis-estimation of fluid power LCOs (Case 2)-density based.

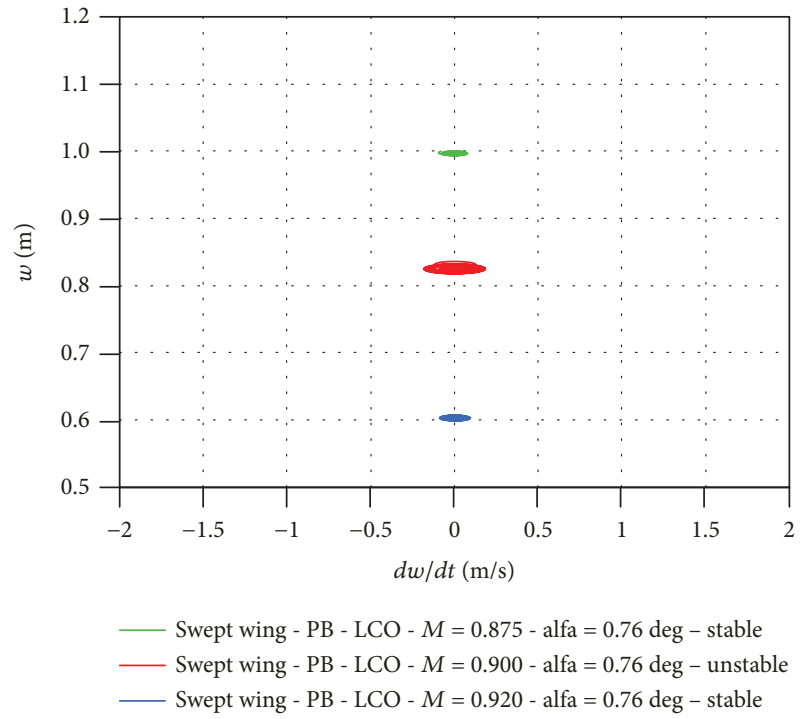

FIGURE 34: FSI analyses of the swept wing-Case 2 (cruise-tip displacement $\mathrm{LCO}-\mathrm{PB}$ ).

effects on the two wings. Figure 33 shows a comparison of the LCOs related to the power that the fluid supplied to the structure, for the same postcritical conditions. For the curved wing, the level and rate of power growth indicate the physics of a classical flutter phenomenon, while a totally different physical situation can be observed for the swept wing.

Similar considerations can be made considering the results related to the pressure-based FSI analyses. For example, Figures 34 and 35 show the estimated oscillation cycles computed for the vertical displacement at the tip leading edge of the wings.

For the swept wing, Figure 36 compares the displacement histories obtained, at cruise altitude, with the density-based and pressure-based options. In this case, the value of the

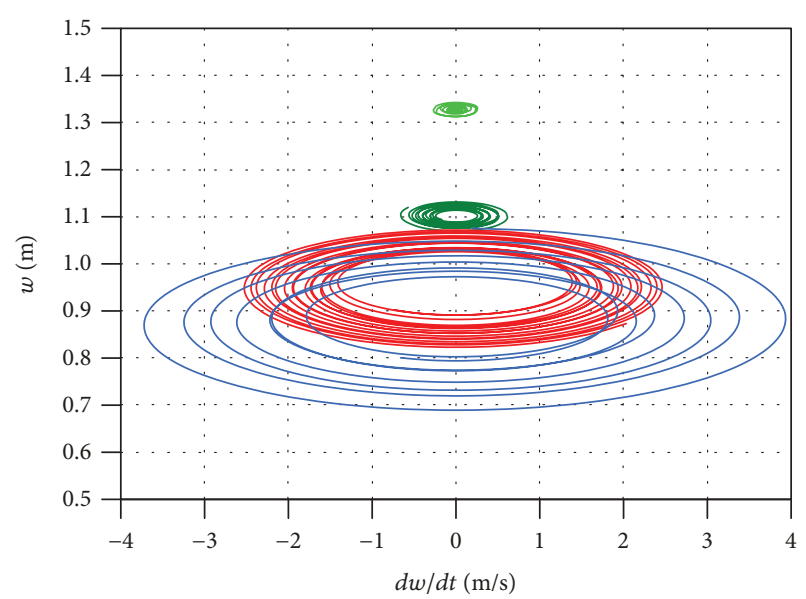

Curved wing - PB - LCO - $M=0.900-$ alfa $=1.15$ deg - stable

Curved wing - PB - LCO - $M=0.925$ - alfa $=1.15 \mathrm{deg}$ - stable

- Curved wing - PB - LCO - $M=0.940$ - alfa $=1.15 \mathrm{deg}$ - unstable

- Curved wing - PB - LCO - $M=0.948$ - alfa $=1.15$ deg - unstable

FIgURE 35: FSI analyses of the curved wing-Case 2 (cruise-tip displacement $\mathrm{LCO}-\mathrm{PB}$ ).

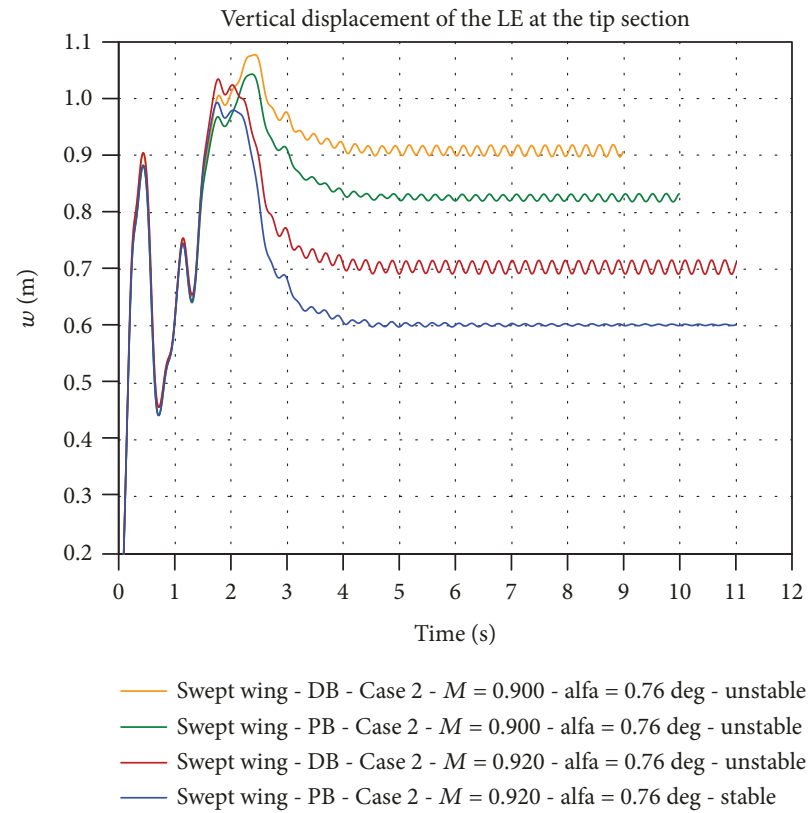

FIgURE 36: FSI DB and PB-displacement histories at the LE of the swept-wing tip (Case 2, $\alpha=0.76^{\circ}$ ).

angle of attack is $\alpha=0.76^{\circ}$. In addition, Figure 37 shows the displacement histories obtained with the density-based option, but for an increased value of the angle of attack, say $\alpha=0.977^{\circ}$. From these histories, the damping parameters represented in Figure 26 were estimated.

The aeroelastic behaviour of the two wings above the instability conditions can be better understood by observing the following animation files: Swept-Case_2-Cruise- $M=$ 0.90 and Curved-Case_2-Cruise- $M=0.948$. Buffeting (flutter-buffet) of the swept wing predominantly involves a 


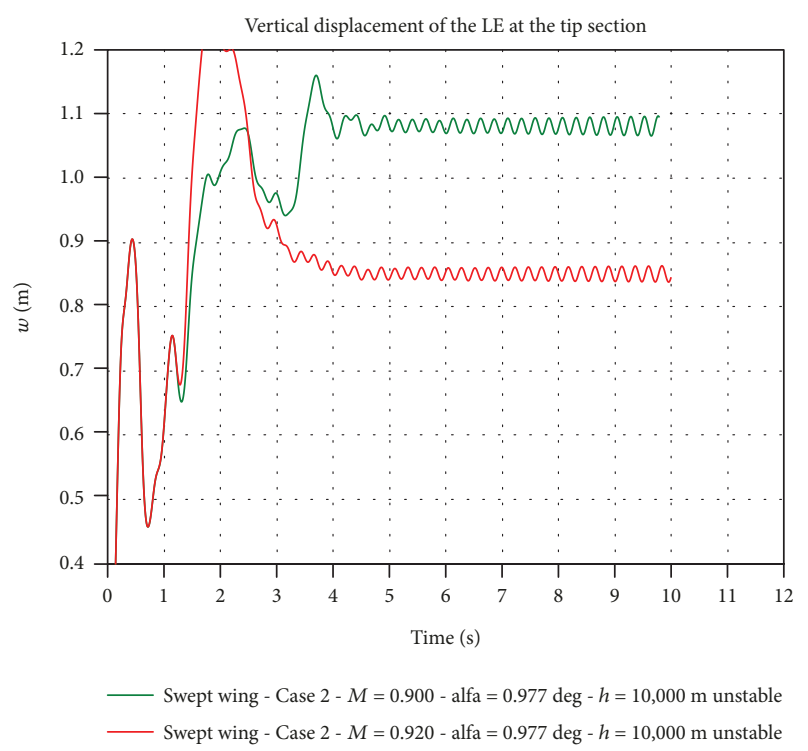

FIGURE 37: FSI DB-displacement histories at the LE of the swept-wing tip (Case 2, $\alpha=0.977^{\circ}$ ).

bending oscillation, while the flutter of the curved wing involves bending and torsion. For example, the variation in time of the pressure coefficient along a section profile of the wings close to the tip zones can be observed in the following animation files: Swept-Case_2-Cp_93\%Cruise-alfa $=0.977 \_$deg $-M=0.9$ and Curved-Case_2-Cp_ 94\%-Cruise-alfa $=1.15$ _deg- $M=0.948$. As mentioned for Case 1, all the animation files shown for Case 2 refer to the results obtained with the density-based solution.

From a qualitative point of view, the different nonlinear dynamic behaviour of the two wings can be explained by looking at Figures 7-11. For a fully transonic regime, the supersonic zones around the wings with the same Mach number and the same $C_{L}$ have a different dimension and shape, especially in the external portion of the wings where, in the FSI analyses, the elasticity of the models plays a more important role. Both the amount of energy stored and the amount of energy dissipated in a transonic flow field are higher in the case of a swept planform with respect to a curved one, and as a consequence a stronger nonlinearity affects the aeroelastic response of the swept wing.

Our results also show that if the effects of nonlinearities due to transonic aerodynamics are present and play an important role, the power of aerodynamic forces acting on a wing, close to the stability margin, is small and in this case there is an interaction between flutter and buffet. If the level of transonic flow nonlinearity is weaker, this interaction is also weaker, as happens for the curved wing in Case 1 at cruise flight conditions. In fact, in Case 1 the swept wing operates in a fully subsonic field and a classical flutter occurs without any evidence of nonlinearity effects, as shown in Figures 22, 24, and 25.

On the other hand, the curved wing operates in a transonic field which helps to lower the level of oscillations even above the stability margin and at least for the first cycles of the dynamic response (see Figures 23, 24, and 24: Figures 24 and 25 refer to the working point with Mach $=0.90$ in Figure 20). However, in this case the nonlinearity is not strong enough to control the characteristics of the dynamic stability of the wing and, as a consequence, for the curved wing, a classical flutter occurs. A comparison of the fluid power oscillation cycles of Case 1 and Case 2 (Figures 25 and 33) confirms this last assumption, and demonstrates that the swept wing more clearly suffers from the effects of the transonic aerodynamics.

Finally, although in the present study, beyond the examined instability conditions, the computed LCOs are not fully stable, from a technical point of view the results obtained are in good agreement with the theoretical behaviour of nonlinear aeroelastic systems as discussed in the literature. In addition, they do not depend significantly on the numerical methodologies that can be used to compute the transonic pressure field.

\section{Conclusions}

In order to define an innovative configuration for future generations of fixed-wing aircraft, rigid CFD analyses and dynamic FSI analyses were carried out to compare the aerodynamic and aeroelastic performances of two high-aspect-ratio wings: a curved planform wing and a conventional swept wing. The two analysed half wings have the typical dimensions of a long-range transport aircraft.

For the analyses, a commercial software was used. As a reference, polar drag curves of the two wings were constructed and compared for a conventional cruise flight condition $(h=10,000 \mathrm{~m}, \mathrm{Mach}=0.85)$. The numerical models used in this phase of the research were assumed as rigid and two highly refined structured CFD meshes were adopted (these meshes are made up of about 6.5 million cells and/or nodes). As demonstrated in our studies, the curved wing provides a notable drag reduction (the pressure component of drag, i.e., the wave drag is primarily reduced) due to the different effects of the transonic phenomena. As a simple case study, by adopting the computed polar curves, the fuel saving was estimated for a cruise flight at constant altitude: about two tons of fuel are saved and consequently pollution is reduced.

A sensitivity study demonstrated that by adopting coarser CFD meshes (these meshes are now composed of about 0.4 million cells) the lift coefficient is affected by an error of about $10 \%$. In terms of comparative aeroelastic analyses and assuming that this level of error is acceptable, FSI simulations provided a series of new numerical data that enrich previous published results.

The analysis of the reference literature provided a basis to highlight and to interpret the differences in the aeroelastic behaviour of the two half-wing models. It is well known that nonlinear phenomena affect the dynamic responses of lifting surfaces in a transonic flow field, and a bifurcation diagram for limit cycle oscillations can be defined where the flutter speed identifies the bifurcation point. In general, if nonlinearities are weak enough, postcritical stable paths of this diagram are very flat: i.e., the amplitude of the self-sustained oscillations tend to increase very rapidly for small increments 
in the speed (or Mach) parameter. The opposite occurs for strong nonlinearities. In the former case, the instability condition concerns a classical flutter, while in the latter a flutter-buffet instability (single-degree-of-freedom flutter) occurs. These well-distinct behaviours were observed in the present study. Assuming all the other technical parameters as similar, in a transonic flight condition the half swept-wing model becomes unstable for a smaller value of Mach and a flutter-buffet phenomenon characterizes the form of its instability.

The curved wing suffers fewer transonic effects, and the unstable condition is reached for a higher value of Mach number for which a classical flutter occurs. Following a procedure that is well established in the literature, the comparisons of LCO for the leading-edge wing tip displacement, lift coefficient, and power of aerodynamic forces demonstrate how a curved planform, in a transonic flow condition, can favourably influence the self-sustained pressure field oscillations which are the basis of the high-speed buffet and flutter-buffet interaction phenomena of wings.

\section{Data Availability}

The data used to support the findings of this study are available from the corresponding author upon request.

\section{Conflicts of Interest}

The authors declare that there are no conflicts of interest regarding the publication of this paper.

\section{Supplementary Materials}

Supplementary 1. Swept-Case_1-Sea_Level-M=0.45: the animation file shows the dynamic instability (classical bending-torsion flutter) of the swept-wing model for Case 1 (see Table 3 of Reference [20]) in a subsonic flight condition ( $M=0.45$ of Figure 20 of the present paper) at sea level. The animation file reproduces the displacement history of the FSI analysis (density based).

Supplementary 2. Curved-Case_1-Sea_Level-M=0.5: the animation file shows the dynamic instability (classical bending-torsion flutter) of the curved-wing model for Case 1 (see Table 3 of Reference [20]) in a subsonic flight condition ( $M=0.50$ of Figure 20 of the present paper) at sea level. The animation file reproduces the displacement history of the FSI analysis (density based).

Supplementary 3. Swept-Case_1-Cruise- $M=0.8$ : the animation file shows the dynamic instability (classical bending-torsion flutter) of the swept-wing model for Case 1 (see Table 3 of Reference [20]) in a high-subsonic flight condition ( $M=0.8$ of Figure 20 of the present paper) at cruise altitude $(h=10,000 \mathrm{~m})$. In this case, the flow around the wing is still fully subsonic. The animation file reproduces the displacement history of the FSI analysis (density based).

Supplementary 4. Curved-Case_1-Cruise-M=0.9: the animation file shows the dynamic instability (classical bending-torsion flutter) of the curved-wing model for Case
1 (see Table 3 of Reference [20]) in a transonic flight condition ( $M=0.9$ of Figure 20 of the present paper) at cruise altitude $(h=10,000 \mathrm{~m})$. The animation file reproduces the displacement history of the FSI analysis (density based).

Supplementary 5. Swept-Case_2-Cruise- $M=0.90$ : the animation file shows the dynamic instability of the swept-wing model for Case 2 (see Table 3 of Reference [20]) in transonic flight condition ( $M=0.9$ of Figure 26 of the present paper, alfa $=0.977 \mathrm{deg})$ at cruise altitude $(h=10,000 \mathrm{~m})$. The animation file reproduces the displacement history of the FSI analysis (density based). A single-degree-of-freedom flutter is highlighted: the buffeting involves a structural bending mode of the wing model. The amplitude of self-sustained oscillations is very small compared with the dimension of the tip chord.

Supplementary 6. Curved-Case_2-Cruise- $M=0.948$ : the animation file shows the dynamic instability of the curved-wing model for Case 2 (see Table 3 of Reference [20]) in transonic flight condition $(M=0.948$ of Figure 26 of the present paper, alfa $=1.15 \mathrm{deg}$ ) at cruise altitude $(h=10,000 \mathrm{~m})$. The animation file reproduces the displacement history of the FSI analysis (density based). In this case, a classical bending-torsion flutter is highlighted.

Supplementary 7. Swept-Case_2-Cp_93\%-Cruise-alfa = 0.977_deg- $M=0.9$ : the animation file shows the variation of pressure coefficient $\left(C_{p}\right)$ distribution on the profile at $93 \%$ of the span of the swept-wing model for Case 2 (see Table 3 of Reference [20]) in transonic flight condition $(M=0.9$ of Figure 26 of the present paper, alfa $=0.977 \mathrm{deg}$ ) at cruise altitude $(h=10,000 \mathrm{~m})$. The animation file reproduces the results of the FSI analysis (density based). A single cycle of oscillations has been shown: due to the buffeting phenomena of the swept-wing model, the variation of $C_{p}$ vs. time is not so strong.

Supplementary 8. Curved-Case_2-C ${ }_{p-94 \%-C r u i s e-a l f a}=$ $1.15 \_$deg $-M=0.948$ : the animation file shows the variation of pressure coefficient $\left(C_{p}\right)$ distribution on the profile at $94 \%$ of the span of the curved-wing model for Case 2 (see Table 3 of Reference [20]) in transonic flight condition $(M=0.948$ of Figure 26 of the present paper, alfa $=1.15 \mathrm{deg}$ ) at cruise altitude $(h=10,000 \mathrm{~m})$. The animation file reproduces the results of the FSI analysis (density based). A single cycle of oscillations has been shown: in this case, due to the classical flutter phenomena of the curved-wing model, the variation of $C_{p}$ vs. time is very important.

\section{References}

[1] SIEMENS, "Siemens, Airbus and Rolls-Royce team up for electric future of flight," November 2017, https://www.siemens. com/press/en.

[2] BOEING, "Introducing the 777X," January 2018, http:// www.boeing.com/commercial/777x/.

[3] M. Chiarelli, A. Lanciotti, and L. Lazzeri, "Compression behaviour of flat stiffened panels made of composite material," Composite Structures, vol. 36, no. 1-2, pp. 161-169, 1996. 
[4] Y. Shi, S. R. Hallett, and M. Zhu, "Energy harvesting behaviour for aircraft composites structures using macro-fibre composite: part I-integration and experiment," Composite Structures, vol. 160, pp. 1279-1286, 2017.

[5] M. R. Chiarelli, V. Binante, S. Botturi et al., "On the active deformations of hybrid specimens," Aircraft Engineering and Aerospace Technology, vol. 88, no. 5, pp. 676-687, 2016.

[6] M. Akbar and J. L. Curiel-Sosa, "Piezoelectric energy harvester composite under dynamic bending with implementation to aircraft wing-box structure," Composite Structures, vol. 153, pp. 193-203, 2016.

[7] J. Serra, J. E. Pierré, J. C. Passieux, J. N. Périé, C. Bouvet, and B. Castanié, "Validation and modeling of aeronautical composite structures subjected to combined loadings: the VERTEX project. Part 1: experimental setup, FE-DIC instrumentation and procedures," Composite Structures, vol. 179, pp. 224244, 2017.

[8] I. Dayyani, A. D. Shaw, E. I. Saavedra Flores, and M. I. Friswell, "The mechanics of composite corrugated structures: a review with applications in morphing aircraft," Composite Structures, vol. 133, pp. 358-380, 2015.

[9] L. Vertuccio, L. Guadagno, G. Spinelli, P. Lamberti, V. Tucci, and S. Russo, "Piezoresistive properties of resin reinforced with carbon nanotubes for health-monitoring of aircraft primary structures," Composites Part B: Engineering, vol. 107, pp. 192-202, 2016.

[10] J. A. Rosero, J. A. Ortega, E. Aldabas, and L. Romeral, "Moving towards a more electric aircraft," IEEE Aerospace and Electronic Systems Magazine, vol. 22, no. 3, pp. 3-9, 2007.

[11] F. Schettini, E. Denti, G. Di Rito, and R. Galatolo, "Simulation of an all-electric flight control system for the evaluation of power consumption," in Proceedings of the 29th Congress of the International Council of the Aeronautical Sciences (ICAS '14), pp. 4064-4071, Russian Federation, September 2014.

[12] F. Schettini, E. Denti, and G. Di Rito, "Development of a simulation platform of all-electric aircraft on-board systems for energy management studies," Aeronautical Journal, vol. 121, no. 1239, pp. 710-719, 2017.

[13] J. A. Hetrick, R. F. Osborn, S. Kota, P. M. Flick, and D. B. Paul, "Flight testing of mission adaptive compliant wing," in 48th AIAA/ASME/ASCE/AHS/ASC Structures, Structural Dynamics, and Materials Conference, Honolulu, Hawaii, USA, April 2007.

[14] R. F. Osborn, S. Kota, G. Ervin, H. Youngren, and P. Flick, "Mission adaptive compliant wing: design, performance and flight test results," in 50th AIAA/ASME/ASCE/AHS/ASC Structures, Structural Dynamics, and Materials Conference, Palm Springs, California, USA, May 2009.

[15] V. Cipolla, A. Frediani, K. Abu Salem, V. Binante, E. Rizzo, and M. Maganzi, "Preliminary transonic CFD analyses of a PrandtlPlane transport aircraft," Transportation research Procedia, vol. 29, pp. 82-91, 2018.

[16] R. Cavallaro and L. Demasi, "Challenges, ideas, and innovations of joined-wing configurations: a concept from the past, an opportunity for the future," Progress in Aerospace Sciences, vol. 87, pp. 1-93, 2016.

[17] M. R. Chiarelli, M. Cagnoni, M. Ciabattari, M. De Biasio, and A. Massai, "High aspect ratio wing with curved planform: CFD and FE analyses," in Proceedings of the 27th Congress of the International Council of the Aeronautical Sciences (ICAS '10), pp. 1524-1533, Nice, France, September 2010.
[18] M. R. Chiarelli, G. Lombardi, and A. Nibio, "A straight wing and a forward swept wing compared with a curved planform wing in the transonic regime," in Proceedings of the International Conference of the European Aerospace Societies (CEAS '11), Venice, Italy, October 2011.

[19] M. R. Chiarelli, M. Ciabattari, M. Cagnoni, and G. Lombardi, "Fluid-structure interaction analyses of wings with curved planform: preliminary aeroelastic results," in Proceedings of the International Conference of the European Aerospace Societies (CEAS '13), Linköping, Sweden, June 2013.

[20] M. R. Chiarelli and S. Bonomo, "Aeroelastic analysis of wings in the transonic regime: planform's influence on the dynamic instability," International Journal of Aerospace Engineering, vol. 2016, Article ID 3563684, 13 pages, 2016.

[21] ANSYS Inc, “ANSYS-FLUENT user's manual, Rel 15,” 2013.

[22] E. Stanewsky and D. Basler, "Experimental investigation of buffet onset and penetration on a supercritical airfoil at transonic speed," in AGARD CP-483, Aircraft Dynamic Loads Due to Flow Separation, p. 11, Sorrento, Italy, April 1990.

[23] E. Obert, Aerodynamic Design of Transport Airplane, IOS Press BV, Amsterdam, 2009.

[24] E. Carson Yates Jr, Agard Standard Aeroelastic Configuration for Dynamic Response I-Wing 445.6, AGARD-R-765, 1988.

[25] J. Bohbot, J. Garnier, S. Toumit, and D. Darracq, "Computation of the flutter boundary of an airfoil with a parallel Navier-Stokes solver," in 39th Aerospace Sciences Meeting and Exhibit, Reno, NV, USA, January 2001.

[26] E. H. Dowell and D. Tang, "Nonlinear aeroelasticity and unsteady aerodynamics," AIAA Journal, vol. 40, no. 9, pp. 1697-1707, 2002.

[27] E. Dowell, J. Edwards, and T. Strganac, "Nonlinear aeroelasticity," Journal of Aircraft, vol. 40, no. 5, pp. 857-874, 2003.

[28] C. R. dos Santos, D. A. Pereira, and F. D. Marques, "On limit cycle oscillations of typical aeroelastic section with different preset angles of incidence at low airspeeds," Journal of Fluids and Structures, vol. 74, pp. 19-34, 2017.

[29] J. B. McDevitt and A. F. Okuno, "Static and dynamic pressure measurements on a NACA 0012 airfoil in the Ames High Reynolds Number Facility," NASA Technical Paper 2485, 1985.

[30] B. H. K. Lee, "Oscillatory shock motion caused by transonic shock boundary-layer interaction," AIAA Journal, vol. 28, no. 5, pp. 942-944, 1990.

[31] B. H. K. Lee, "Self-sustained shock oscillations on airfoils at transonic speeds," Progress in Aerospace Sciences, vol. 37, no. 2, pp. 147-196, 2001.

[32] Q. Xiao, H. M. Tsai, and F. Liu, "Numerical study of transonic buffet on a supercritical airfoil," AIAA Journal, vol. 44, no. 3, pp. 620-628, 2006.

[33] J. D. Crouch, A. Garbaruk, and D. Magidov, "Predicting the onset of flow unsteadiness based on global instability," Journal of Computational Physics, vol. 224, no. 2, pp. 924-940, 2007.

[34] J. D. Crouch, A. Garbaruk, D. Magidov, and A. Travin, "Origin of transonic buffet on aerofoils," Journal of Fluid Mechanics, vol. 628, p. 357, 2009.

[35] J. Xiong, F. Liu, and S. Luo, "Computation of NACA0012 airfoil transonic buffet phenomenon with unsteady NavierStokes equations," in 50th AIAA Aerospace Sciences Meeting including the New Horizons Forum and Aerospace Exposition, Nashville, Tennesse, USA, January 2012. 
[36] S. Illi, T. Lutz, and E. Krämer, "On the capability of unsteady RANS to predict transonic buffet," in Proceedings of the Third Symposium "Simulation of Wing and Nacelle Stall", Braunschweig, Germany, June 2012.

[37] C. Q. Gao, W. W. Zhang, Y. L. Liu, Z. Y. Ye, and Y. W. Jiang, "Numerical study on the correlation of transonic singledegree-of-freedom flutter and buffet," Science China Physics, Mechanics \& Astronomy, vol. 58, no. 8, article 84701, 2015.

[38] J. Liu and Z. Yang, "Numerical study on transonic shock oscillation suppression and buffet load alleviation for a supercritical airfoil using a microtab," Engineering Applications of Computational Fluid Mechanics, vol. 10, no. 1, pp. 529-544, 2016.

[39] D. E. Raveh, "Numerical study of an oscillating airfoil in transonic buffeting flows," AIAA Journal, vol. 47, no. 3, pp. 505$515,2009$.

[40] M. Iovnovich and D. E. Raveh, "Transonic unsteady aerodynamics in the vicinity of shock-buffet instability," Journal of Fluids and Structures, vol. 29, pp. 131-142, 2012.

[41] D. E. Raveh and E. H. Dowell, "Aeroelastic responses of elastically suspended airfoil systems in transonic buffeting flows," AIAA Journal, vol. 52, no. 5, pp. 926-934, 2014.

[42] W. Zhang, C. Gao, Y. Liu, Z. Ye, and Y. Jiang, "The interaction between flutter and buffet in transonic flow," Nonlinear Dynamics, vol. 82, no. 4, pp. 1851-1865, 2015.

[43] C. Gao, W. Zhang, and Z. Ye, "A new viewpoint on the mechanism of transonic single-degree-of-freedom flutter," Aerospace Science and Technology, vol. 52, pp. 144-156, 2016.

[44] C. Gao, W. Zhang, X. Li et al., "Mechanism of frequency lock-in in transonic buffeting flow," Journal of Fluid Mechanics, vol. 818, pp. 528-561, 2017.

[45] N. F. Giannelis and G. A. Vio, "Investigation of frequency lock-in phenomena on a supercritical aerofoil in the presence of transonic shock oscillations," in Proceedings of the International Forum on Aeroelasticity and Structural Dynamics (IFASD '17), Como, Italy, June 2017.

[46] A. Mannarino and P. Mantegazza, "Nonlinear aerodynamic reduced order modeling by discrete time recurrent neural networks," Aerospace Science and Technology, vol. 47, pp. 406419, 2015.

[47] J. Dandois, "Experimental study of transonic buffet phenomenon on a 3D swept wing," Physics of Fluids, vol. 28, no. 1, article 016101, 2016.

[48] F. Plante, J. Dandois, F. Sartor, and E. Laurendeau, "Study of three-dimensional transonic buffet on swept wings," in 35th AIAA Applied Aerodynamics Conference, Denver, Colorado, USA, June 2017.

[49] M. Iovnovich and D. E. Raveh, "Numerical study of shock buffet on three-dimensional wings," AIAA Journal, vol. 53, no. 2, pp. 449-463, 2015.

[50] F. Sartor and S. Timme, "Reynolds-Averaged Navier-Stokes simulations of shock buffet on half wing-body configuration," in 53rd AIAA Aerospace Sciences Meeting, Kissimmee, Florida, USA, January 2015.

[51] N. F. Giannelis, G. A. Vio, and O. Levinski, "A review of recent developments in the understanding of transonic shock buffet," Progress in Aerospace Sciences, vol. 92, pp. 39-84, 2017.

[52] I. W. Tjatra, R. K. Kapania, and B. Grossman, "Structural non-linearity effects on flutter of a swept wing in transonic flows," Computing Systems in Engineering, vol. 3, no. 1-4, pp. 131-138, 1992.

[53] F. Liu, J. Cai, Y. Zhu, H. M. Tsai, and A. S. F. Wong, "Calculation of wing flutter by a coupled fluid-structure method," Journal of Aircraft, vol. 38, no. 2, pp. 334-342, 2001.

[54] L. Cavagna, G. Quaranta, and P. Mantegazza, “Application of Navier-Stokes simulations for aeroelastic stability assessment in transonic regime," Computers and Structures, vol. 85, no. 11-14, pp. 818-832, 2007.

[55] O. O. Bendiksen, "Transonic limit cycle flutter of high-aspectratio swept wings," Journal of Aircraft, vol. 45, no. 5, pp. 1522 1533, 2008.

[56] F. Afonso, J. Vale, E. Oliveira, F. Lau, and A. Suleman, "A review on non-linear aeroelasticity of high aspect-ratio wings," Progress in Aerospace Sciences, vol. 89, pp. 40-57, 2017.

[57] D. P. Raymer, "Aircraft design: a conceptual approach," in Fifth Edition, AIAA Education Series, Reston, Virginia, USA, 2012. 


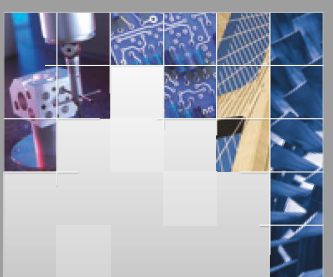

\section{Enfincering}
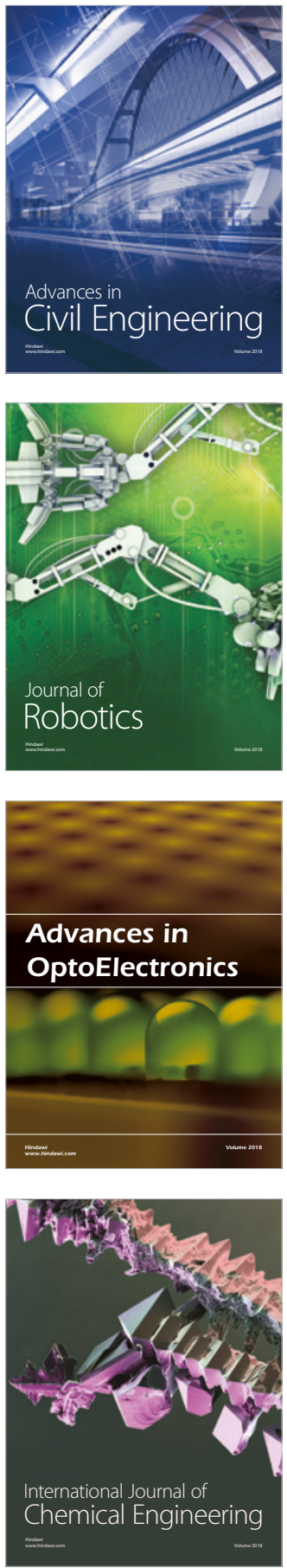

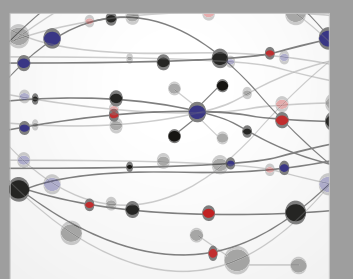

\section{Rotating \\ Machinery}

The Scientific World Journal

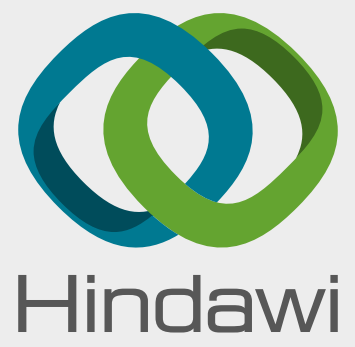

Submit your manuscripts at

www.hindawi.com
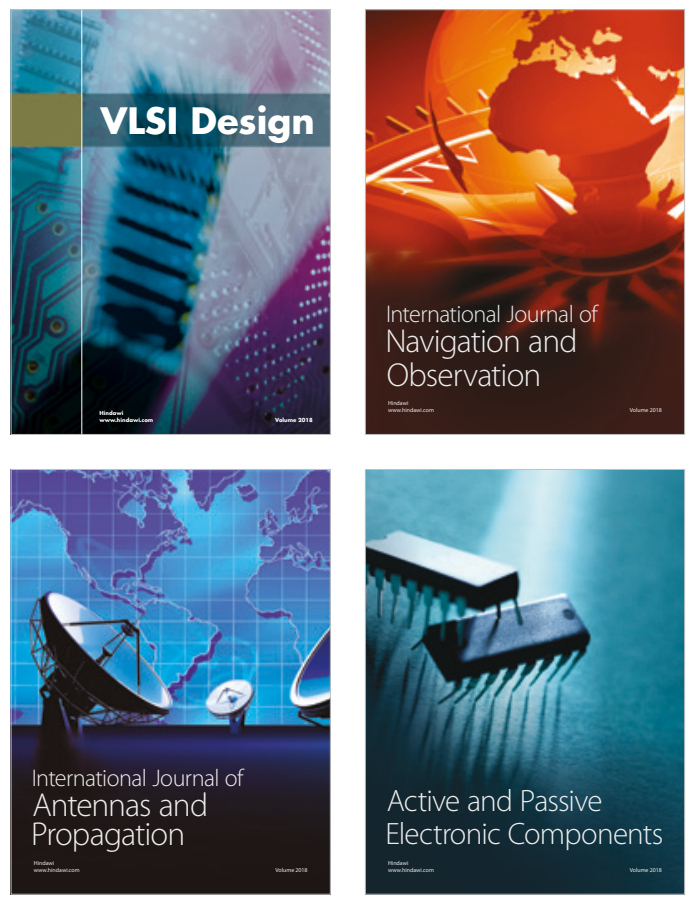
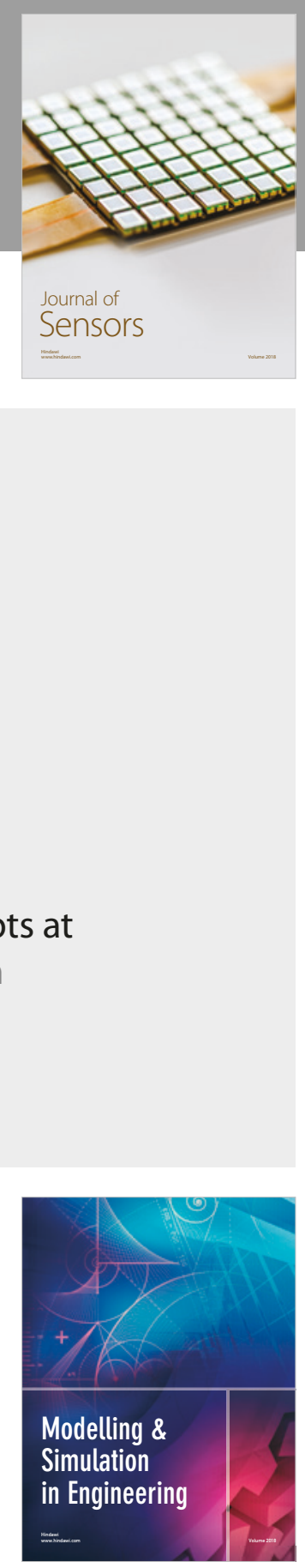

\section{Advances \\ Multimedia}
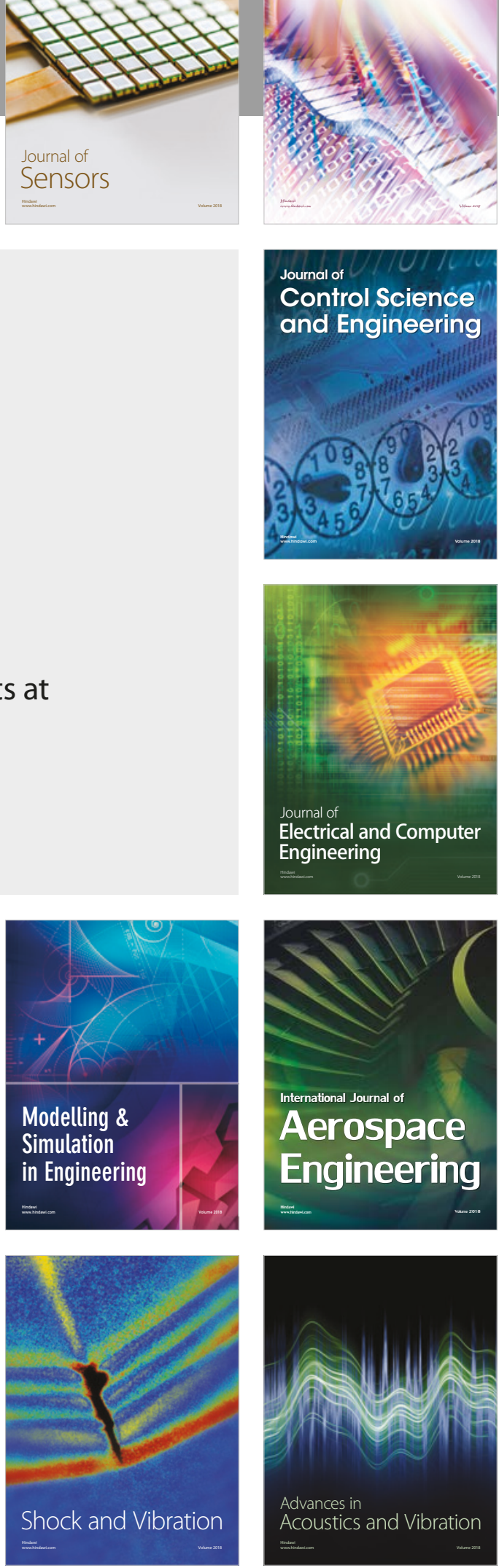